\title{
Elaboração do panorama do mercado segurador brasileiro em relação à regulamentação internacional de solvência
}

\section{Elaboration of the panorama of the Brazilian insurance market in relation to international solvency regulation}

Análisis del panorama del mercado asegurador brasileño en relación a la regulación internacional de solvencia

\section{Edson Roberto Macohon}

Doutor em Ciências Contábeis e Administração pela

Universidade Regional de Blumenau (FURB)

Professor do Departamento de Ciências Contábeis da

Universidade Estadual do Centro-Oeste (UNICENTRO) Campus Irati

Endereço: PR 153 - KM 07 - Riozinho - Cx. Postal, 21

CEP: 85500-000 - Irati/PR - Brasil

E-mail: ermacohon@unicentro.br

Telefone: (42) 999742866

\section{Jonas Fernando Petry}

Doutor em Ciências Contábeis e Administração pela

Universidade Regional de Blumenau (FURB)

Professor do Departamento de Administração da

Universidade Federal do Amazonas (UFAM/INC/BC)

Endereço: Av. Patrício Caldeira de Andrade, n॰ 1596 Bairro Capoeiras

CEP: 88085-150 - Florianópolis/SC - Brasil

E-mail: jonaspetry@brturbo.com.br

Telefone: (97) 991840212

\section{Francisco Carlos Fernandes}

Doutor em Controladoria e Contabilidade pela Faculdade de Economia, Administração e Contabilidade (FEA) da Universidade de São Paulo (USP)

Professor da Escola Paulista de Política, Economia e Negócios (EPPEN) da Universidade Federal de São Paulo (UNIFESP).

Endereço: Rua Angélica, $n^{\circ}$ 100, Jardim das Flores

CEP: 06110-295 - Osasco/SP - Brasil

E-mail: francisco.fernandes@unifesp.br

Telefone: (11) 2284-6900

Artigo recebido em 22/10/2015. Revisado por pares em 29/08/2016. Reformulado em 26/12/2016. Recomendado para publicação em 16/03/2017 por Carlos Eduardo Facin Lavarda (Editor-Chefe). Publicado em 30/04/2017. 


\section{Resumo}

O objetivo da pesquisa foi analisar o panorama do mercado segurador brasileiro em relação à regulamentação internacional de solvência. Quanto aos objetivos, este estudo se caracteriza como pesquisa descritiva, e quanto aos procedimentos, é documental. A população são as 180 seguradoras brasileiras credenciadas na Susep que publicam suas demonstrações financeiras. A análise dos dados é qualitativa, que se dá por meio da análise de conteúdo dos textos selecionados das notas explicativas e seu enquadramento nas 13 perspectivas de Taylor (2012). A pesquisa constatou que, embora haja crescente conscientização das partes interessadas na governança e gestão de risco das seguradoras brasileiras, ainda é necessário haver melhorias. As informações de avaliação de risco e solvência foram evidenciadas de forma bastante limitada devido às exigências da Susep. Poucas empresas detalharam o perfil de risco específico, os limites de tolerância de risco, bem como explicações acerca das provisões técnicas. Ademais, nenhuma seguradora pesquisada demonstrou dificuldades quanto aos limites de capital mínimo requerido pelo Solvency II.

Palavras-chave: Seguradoras, Gestão de risco, Regulação do risco, Solvency II.

\section{Abstract}

The research objective was to analyze the view of the Brazilian insurance market in relation to international solvency regulation. This study is characterized as to the goals as descriptive, and as to the procedures it is documentary. The population is 180 accredited Brazilian insurers accredited by SUSEP that publish their financial statements. Data analysis is qualitative, which is carried out through the content analysis of the selected explanatory notes and their place within the 13 prospects of Taylor (2012) texts. The survey found that although there is a growing awareness of stakeholders in governance and risk management of the Brazilian insurance companies, improvements are still necessary. The information risk assessment and solvency were shown quite so limited to SUSEP requirements. Few companies have detailed the specific risk profile, the limits of tolerance to risk as well as explanations of technical provisions. Furthermore, no insurer surveyed demonstrated difficulties as to the limits of the minimum capital required by Solvency II.

Keywords: Insurance; Risk management; Risk regulation; Solvency II

\section{Resumen}

El objetivo de esta investigación fue analizar el panorama del mercado asegurador brasileño en relación a la regulación internacional sobre solvencia. De acuerdo con los objetivos, este estudio se caracteriza como descriptivo y como documental, por los procedimientos utilizados. El universo fueron 180 aseguradoras brasileñas acreditadas en la Superintendencia de Seguros Privados (SUSEP) que publican sus estados financieros. El análisis de los datos fue cualitativo, realizado por medio del análisis de contenido de textos seleccionados de las notas explicativas y su encuadramiento en las 13 perspectivas de Taylor (2012). La investigación constató que, aunque haya una creciente concientización de las partes interesadas en la gobernanza y en la gestión de riesgo de las aseguradoras brasileñas, aún hay necesidad de mejorías. Las informaciones de evaluación de riesgo y solvencia se evidenciaron de forma bastante limitada en cuanto a las exigencias de la SUSEP. Pocas empresas detallaron el perfil de riesgo especifico, los límites de tolerancia de riesgo y las explicaciones acerca de las provisiones técnicas. Además, ninguna aseguradora investigada demostró dificultades con respecto a los límites de capital mínimo requerido por el Solvency II.

Palabras clave: Seguradoras; Gestión de riesgo; Regulación del riesgo; Solvencia II

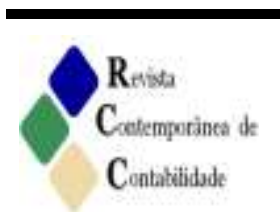




\section{Introdução}

Nos últimos anos, os eventos no setor financeiro da economia mundial têm mostrado que a crise financeira é, em grande parte, provocada por leis que não estão em conformidade com os princípios básicos de riscos. Por isso, é importante que os responsáveis compreendam a natureza dos riscos que a sociedade está suscetível (VAVROVA; SLOVA, 2012). As pessoas, empresas e entidades em geral estão expostas a vários riscos que potencialmente podem levar a indesejáveis consequências financeiras. No entanto, nos últimos anos tem havido aumento da atenção da indústria de seguros para a avaliação de mercado dos passivos de seguros e a quantificação de riscos de seguros. Para tanto, fatos importantes desse desenvolvimento são a introdução das IFRS e do Solvency (PLAT, 2011). O estudo de Badea e Novac (2001) concebe que a gestão de risco tem sido considerada um processo que é aplicado diariamente por todos, seja pessoa física, seja jurídica, por vezes mesmo sem perceber.

A nova regulamentação europeia, o Solvency II, inexoravelmente aumenta a necessidade de uma gestão eficaz dos riscos operacionais e de desenvolvimento e implementação de métodos estruturados de análise. É também revista a técnica clássica do valor, a modelagem em Risco (VaR), e outros métodos para análise e quantificação do risco operacional para as seguradoras (TORRE-ENCISO; BARROS, 2012).

As companhias de seguros enfrentam diariamente inúmeros riscos decorrentes da própria indústria de seguros, bem como os riscos decorrentes de operações de seguros da empresa, como colocação de fundos disponíveis, as obrigações sob os prêmios de seguros e a harmonização de recursos (ILIC; AVDALOVIC; OBADOVIC, 2011). Para Torre-Enciso e Barros (2012), a complexidade dessas empresas vem da natureza de suas operações, que é aceitar os riscos assumidos por outras entidades ou indivíduos. No entanto, uma política coerente de gestão de risco tornou-se vantagem competitiva para as companhias de seguros que perceberam a importância desse processo. Os principais efeitos da implementação de um processo de gerenciamento de riscos consistem na melhor subscrição, em melhores investimentos de recursos da empresa e ainda melhores relações contratuais com os parceiros internacionais (resseguradoras) (BADEA; NOVAC, 2001).

Com uma gestão adequada dos prêmios de seguro, companhias de seguros podem consolidar e melhorar sua posição competitiva no mercado de seguros e, assim, fortalecer a posição e o nível de participação do setor de seguros no mercado financeiro global (ILIC; AVDALOVIC; OBADOVIC, 2011). Segundo Badea e Novac (2011), a gestão eficiente de risco não é implementada por todas as seguradoras porque os custos reais de implementação de uma política de gestão rigorosa de risco são considerados muito elevados para orçamentos limitados (especialmente no caso de pequenas ou médias empresas de seguros). Mesmo que os benefícios a longo prazo sejam óbvios para todos, a primeira fase de implementação é considerada onerosa demais para suportar (BADEA; NOVAC, 2001).

O risco do mercado segurador está na capacidade de solvência das seguradoras, mais especificamente no trade-off entre o custo de cobertura do risco e na capacidade de cobertura do risco mediante a ocorrência de eventos inesperados (MEYRICKE; SHERRIS, 2014). O Solvency II é um novo regime regulamentar de seguros que introduz uma abordagem prudencial de supervisão prospectiva baseada no risco (FLORYSZCZAK; LE COURTOIS; MAJRI, 2016), com abordagens nos novos rácios de capital, novos procedimentos de supervisão e uma transparência eficaz para o mercado (BRYCE et al., 2016).

As empresas de seguros e resseguros devem estender suas ferramentas de modelagem para enfrentar o modelo interno de capital de solvência, assegurando um modelo de gestão que visa uma compreensão completa e holística dos riscos, outorgados pelos órgãos de 
administração ou fiscalização. As companhias de seguros e resseguros devem realizar a sua própria avaliação de risco e solvência, incluindo as necessidades de solvência global, tendo em conta o seu perfil de risco específico, limites de tolerância de risco aprovados e estratégias de negócios (FLORYSZCZAK; LE COURTOIS; MAJRI, 2016). A regulação brasileira das diretrizes da International Association of Insurance Supervisors (IAIS) tem semelhanças com o Solvency II em função da forte presença dos europeus nessa associação (NEVES, 2010). A tendência é que o mercado brasileiro acompanhe o movimento europeu e adote paralelamente as novas regulamentações (MARTINS, 2009).

O mercado segurador brasileiro tem apresentado diferenças nas avaliações prudenciais de risco. Apesar das diferenças, a avaliação dos modelos deve estar ancorada nos novos rácios de capital, novos procedimentos de supervisão e na transparência para o mercado (BRYCE et al., 2016). Com relação ao Solvency II, o contexto de avaliação para companhia de seguro no Brasil não tem sido investigado até o presente. Desta forma, a pesquisa é guiada pela seguinte argumentação: Qual o panorama do mercado segurador brasileiro em relação à regulamentação internacional de solvência? Assim, o objetivo deste trabalho é analisar o panorama do mercado segurador brasileiro em relação à regulamentação internacional de solvência.

O capital-base do mercado de seguros do Brasil é assim dividido: Sociedades seguradoras: R\$15 milhões; EAPC com fins lucrativos: R $\$ 7,2$ milhões; Sociedades de capitalização: $\mathrm{R} \$ 10,8$ milhões, variável por região; e, Resseguradores locais: $\mathrm{R} \$ 60$ milhões (NEVES, 2010). Wolfert (2011) apresenta um panorama dos desafios que as grandes seguradoras do Reino Unido terão para se adaptar ao novo regulamento Solvency II, que entrou em vigor em janeiro de 2013. Alguns profissionais da indústria estimam que o custo para as companhias se ajustarem às novas regras deverá superar 200 milhões de libras, com até 65\% dos gastos sendo direcionados para novas tecnologias.

Assim, é necessária uma análise de custo-benefício adequada que promova a redução dos prêmios de seguros e o incremento dos lucros através do aumento do número de segurados, bem como a ampliação do número de empregados sem colocar a empresa em risco (ILIC; AVDALOVIC; OBADOVIC, 2011). Dessa maneira, o estudo contribui para a literatura financeira das seguintes maneiras: em primeiro lugar, embora tenha havido estudos sobre a regulamentação de solvência em outros países (BADEA; NOVAC, 2001; ILIC; AVDALOVIC; OBADOVIC, 2011; MEYRICKE; SHERRIS. 2014; BRYCE, C. et al., 2016; FLORYSZCZAK; LE COURTOIS; MAJRI, 2016), este artigo é o primeiro a analisar o mercado segurador brasileiro; em segundo lugar, a investigação está relacionada à literatura que analisa o risco de solvência em relação à regulamentação internacional.

O restante deste artigo está estruturado da seguinte forma: a seção 2 fornece uma visão da fundamentação teórica, uma introdução ao Solvency II e o modelo padrão com foco no módulo de risco de mercado; a seção 3 apresenta os métodos e procedimentos de pesquisa qualitativa do modelo padrão Solvency II; os resultados da análise dos dados são discutidos na seção 4, e a seção 5 apresenta a conclusão da pesquisa.

\section{Fundamentação Teórica}

\subsection{Estudos Correlatos}

A pesquisa de Ilic, Avdalovic e Obadovic (2011), intitulada Development of model for insurance risk management and its application to insurance companies operating in the

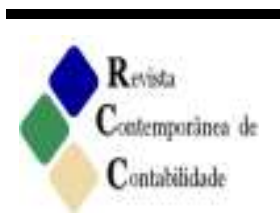


Serbian Market, discorre sobre o tema da gestão de riscos em seguradoras em geral e trata separadamente do risco de seguros e do risco das companhias de seguros. No entanto, tal tratamento separado do risco exclui um terceiro tipo de risco, o qual é definido pelo risco de o risco do seguro ser calculado incorretamente.

O objetivo de Ilic, Avdalovic e Obadovic (2011) é apresentar a relação entre esses dois tipos de risco em seguros e desenvolver um modelo que quantificará a conexão. Em outras palavras, o artigo quantifica um terceiro tipo de risco de seguro chamado de "o risco de avaliação equivocada do risco de seguro", que medirá a perda que as seguradoras enfrentam por causa da avaliação equivocada do risco dos seguros. Os riscos dos seguros muitas vezes não são seguramente calculáveis, exceto em retrospecto, quando o risco já foi transformado em perda mensurável (ILIC; AVDALOVIC; OBADOVIC, 2011).

O artigo de Reij (2008), Managing market risks for Dutch insurers, foca a relação entre as técnicas de gestão de risco nas seguradoras holandesas para reduzir o risco da taxa de juros, um dos componentes mais importantes do risco de mercado e do Solvency II. A questão de pesquisa do estudo de Reij (2008) é: À luz dos atuais desenvolvimentos regulatórios relativos ao ramo de seguros, que técnicas estão disponíveis e são úteis para as seguradoras administrarem o risco da taxa de juros a fim de reduzir o requisito de capital de solvência para o risco de mercado?

Uma das seguradoras entrevistadas por Reij (2008) mencionou que o risco operacional é um componente de grande representatividade no Solvency Capital Requirement (SCR). A pesquisa vislumbrou também que há falta de coerência entre os métodos de cálculo para o seguro de vida e os seguros não vida (REIJ, 2008). Como recomendações para futuras pesquisas, Reij (2008) menciona que é interessante considerar outros riscos além do risco da taxa de juros (e risco de ações).

A investigação de Doff (2008), A Critical Analysis of the Solvency II Proposals, destaca que a comissão europeia publicou o Solvency II com o objetivo de rever profundamente o quadro de supervisão de seguros. A pesquisa testou o quadro Solvency II com sete critérios desenvolvidos por Cummins et al. (1994) descrevendo a melhor forma de duplicar o funcionamento de um mercado eficiente e completo. A pesquisa concluiu que o Solvency II satisfaz a maioria desses critérios. Doff (2008) recomendou uma estrutura mais equilibrada entre os Pilares I, II e III. Dessa forma, os Pilares II e III resolverão alguns problemas do Pilar I, tais como incentivos inadequados de capital (DOFF, 2008). O objetivo do trabalho de Doff (2008) foi testar o quadro Solvency II contra sete critérios para o risk-based capital (RBC); esses requisitos descrevem a melhor forma de duplicar o funcionamento de um mercado eficiente e completo. Os critérios foram desenvolvidos por Cummins et al. (1994) com a introdução das normas do RBC nos EUA.

A pesquisa de Deighton et al. (2009), Governance and risk management in United Kingdom insurance companies, revela que, embora tenha havido crescente conscientização das partes interessadas na governança e gestão de risco nas empresas de seguros do Reino Unido, ainda é necessário ser melhorada. No artigo, apresentou-se o contexto histórico recente de governança para as companhias de seguros do Reino Unido e considerou-se que a gestão de risco das empresas pode reunir os diversos frameworks de controles internos necessários para apoiar a governança.

O estudo de Plat (2011) é uma combinação de artigos sobre várias questões relacionadas com a avaliação e gestão de riscos para as seguradoras. O estudo vislumbrou que a maioria das seguradoras está relatando seus passivos numa base de "valor contábil", em que as premissas econômicas muitas vezes não são diretamente ligadas ao mercado financeiro. Além disso, os reguladores necessitam de capital (solvência) adicional a ser realizado pelas seguradoras, que é 
uma percentagem fixa da reserva, dos prêmios ou das reclamações. Portanto, não se baseiam nos riscos reais da seguradora (PLAT, 2011).

O trabalho de Vavrova e Slova (2012) se concentra na análise dos objetivos específicos da realização e estrutura do regulamento do Solvency II no seu segundo Pilar. O objetivo é comparar a primeira e a atual abordagem da regulamentação dos seguros, o Solvency e o Solvency II, nas condições do mercado de seguros integrado da União Europeia. O estudo afirmou que as seguradoras checas detêm mais capital do que o exigido pelo Solvency II e têm recursos suficientes para obrigações futuras.

A tese de Chan (2010), intitulada "Risco de subscrição frente às regras de solvência do mercado segurador brasileiro", discorreu sobre o Novo Acordo da Basileia, o qual introduziu métodos de apuração da necessidade mínima de capital mais sensível a riscos. Assim, há benefícios às instituições mais bem administradas na medida em que requer menor alocação de capital. No mesmo sentido, no mercado de seguros dos países-membros da União Europeia, atua o projeto Solvency II. O estudo de Chan (2010) investigou ainda a existência de indícios que levam a supor que a nova regulamentação sobre o capital mínimo prejudicou as seguradoras de menor porte (CHAN, 2010).

\subsection{Gestão de Riscos em Seguradoras}

Badea e Novac (2001) descrevem que somente nos últimos anos as seguradoras que, paradoxalmente, são aquelas que comprometem os riscos de outras pessoas e, ao mesmo tempo, aconselham seus clientes na adoção de políticas de gestão adequadas de risco, têm admitido ter problemas com o próprio risco. Uma definição de gestão eficiente do risco tem que abranger tudo, principalmente a análise precisa e complexa de riscos quantificáveis para a definição da seleção, a classificação e os contratos de riscos.

O seguro é um "negócio incerto", caracterizado por uma concorrência em que os prêmios empurram as seguradoras para o desconhecido. A indústria de seguros é um negócio de incerteza, uma vez que as noções de quantificação estão em risco, e o princípio atuarial cada vez mais se evapora em um mercado de seguros competitivo, vibrante e amorfo (ILIC; AVDALOVIC; OBADOVIC, 2011).

O risco operacional é cada vez mais importante na governança corporativa e na gestão de empresas de seguros, que têm mais e mais implicações e interações com os outros riscos, tais como de mercado e de crédito (TORRE-ENCISO; BARROS, 2012). Além dos riscos de seguros, as companhias de seguros também enfrentam os riscos originários do resultado direto das operações da empresa de seguros. Assim como outras entidades financeiras que operam no mercado financeiro, as empresas de seguros enfrentam risco de mercado, risco de maturidade e risco de defasagem estrutural de ativos e passivos. Além disso, há o risco de depositar e investir os ativos da empresa e outros riscos decorrentes de operações, tais como operacional, jurídico e reputacional (ILIC; AVDALOVIC; OBADOVIC, 2011).

Como resultado, a maioria das seguradoras tem de pagar quantias consideráveis a seus segurados no futuro. A empresa deve possuir uma reserva para cobrir isso, que é baseado em uma avaliação desses passivos de seguros no futuro. Ademais, a companhia de seguros está exposta a vários riscos para que detenha capital adicional. Como tal, para a avaliação de passivos de seguros, medir e gerenciar os riscos são dois grandes pilares para a execução de uma companhia de seguros bem-sucedida (PLAT, 2011). A gestão e análise de risco operacional é uma atividade necessária para as seguradoras, apresentando muitas oportunidades para o desenvolvimento e um importante campo de estudo sobre questões conceituais e práticas 
devido à particularidade e à complexidade implícita nesse tipo de risco (TORRE-ENCISO; BARROS, 2012).

A literatura de seguros aborda principalmente vários tipos de risco que as seguradoras estão enfrentando. O IAIS distingue cinco categorias principais que podem ser classificadas em partes. As principais categorias são: risco de subscrição, risco de crédito, risco de mercado que também inclui ALM ou risco incompatibilidade -, risco operacional e risco de liquidez (ILIC; AVDALOVIC; OBADOVIC, 2011). Doff (2008) acrescentou outra categoria de risco: risco do negócio, que é o risco de perdas devidas às mudanças inesperadas no ambiente competitivo da empresa ou na medida em que pode, de forma flexível, se adaptar a essas mudanças.

Ilic, Avdalovic e Obadovic (2011) classificam o risco das seguradoras em duas categorias principais: o risco do seguro e o seguro do risco de empresas. O risco do seguro é o risco principal e representa o risco das seguradoras. Ele pode ser definido como a incapacidade das companhias de seguros de absorver os riscos tomados com base em contratos de seguro celebrados.

Para o requerimento de capital de solvência, destacam-se os seguintes riscos: 1. Risco de subscrição não vida; 2. Risco de subscrição vida; 3. Risco de subscrição saúde; 4. Risco de Mercado; 5. Risco de Crédito; e, 6. Risco Operacional. Estima-se que o risco operacional represente de $15 \%$ a $25 \%$ do risco total de uma seguradora (NEVES, 2010). O capital é dividido em requerimento de capital mínimo (MCR) e requerimento de capital de solvência (SCR). O SCR é um nível mais elevado de capital que a empresa deverá normalmente ter. De acordo com o texto aprovado pelo Parlamento Europeu, o requisito de capital mínimo não deverá ser inferior a $25 \%$ nem superior a $45 \%$ do requisito de capital de solvência (NEVES, 2010).

O estudo de Mango (2007) vai além e destaca que o conceito de risco estratégico (SR) não está bem definido e, portanto, não é bem compreendido. A definição proposta de estratégia é a ciência e a arte de planejamento, usando recursos políticos, econômicos, psicológicos e organizacionais para atingir os principais objetivos organizacionais (MANGO, 2007). Já o risco estratégico de Miller (1992) refere-se a movimentos estratégicos que podem potencialmente mitigar os riscos associados com as incertezas. Miller (1992) considera incertezas estratégicas como impactos imprevisíveis das estratégias (MANGO, 2007). O Quadro 1, que concebe os riscos estratégicos listados por Slywotzky e Drzik (2005) que podem impactar uma seguradora.

\subsection{Solvency II}

A nova regulamentação Solvency II, estruturada em três pilares (requisitos financeiros, de acordo com o nível real de risco assumido pelas seguradoras; mecanismos de controle interno e de transparência de mercado; e disciplina), inexoravelmente aumenta a necessidade de uma gestão eficaz do risco operacional e o desenvolvimento e implementação de novos métodos para sua análise (TORRE-ENCISO; BARROS, 2012; BRYCE et al., 2016). Reij (2008) compara o Solvency II com os padrões antigos (chamados de Solvency I). O novo quadro tem estas duas grandes diferenças: requisitos de capital baseado em risco e avaliação de mercado dos passivos. Esses dois desenvolvimentos deverão ter grande influência sobre a gestão de risco das seguradoras.

O Solvency II leva a uma mudança no capital de solvência necessária para regulamentar as seguradoras. Sob o Solvency II, o chamado capital de solvência (SCR) é baseado no risco, e os valores de mercado dos ativos e passivos são a base para esses cálculos. A diretiva do Solvency II prescreve que a reserva deve ser igual à soma da melhor estimativa e uma margem de risco, e que a melhor estimativa corresponderá à média ponderada da probabilidade de fluxos 
de caixa futuros, tendo em conta o valor do dinheiro no tempo (PLAT, 2011).

\begin{tabular}{|c|c|}
\hline Indústria & $\begin{array}{l}\text { Intensidade de capital; capacidade excedentária; comoditização; desregulamentação; magnitude muito } \\
\text { alta do ciclo de volatilidade do risco. O mercado de seguros sofre todas essas condições }\end{array}$ \\
\hline Tecnologia & Mudança; patentes; magnitude baixa da obsolescência do risco \\
\hline Marca & $\begin{array}{l}\text { Erosão ou colapso; magnitude moderada do risco. Essencialmente, seguros "produtos" são verificações } \\
\text { de sinistros. Portanto, é difícil para as seguradoras diferenciar com base no conteúdo do produto. O } \\
\text { cheque é bom, ou não é, portanto, as seguradoras muitas vezes diferenciam preços e serviços. Se um } \\
\text { interpreta "promessa de marca" da seguradora como incluindo a reputação, então a perda dessa reputação } \\
\text { através da imprensa ou de ações coletivas definitivamente poderia destruir o valor da marca }\end{array}$ \\
\hline Concorrentes & $\begin{array}{l}\text { Rivais globais; magnitude moderada dos concorrentes de risco. Preços predatórios são um risco } \\
\text { significativo, pois a quota de mercado pode ser prejudicada facilmente por seguradoras dispostas a } \\
\text { conceder descontos. A entrada do novo (ou um crescimento significativo em vigor), linhas ou territórios } \\
\text { com expertise de subscrição inadequada, sistemas de preços, capacidade de monitoramento de preços, } \\
\text { capacidades políticas de manutenção, compreensão de exigências regulatórias, manipulação pessoal, etc. } \\
\text { A concorrência destrutiva dos concorrentes simultaneamente visando ao mesmo segmento de mercado } \\
\text { (planejamento unilateral, a não antecipar as mudanças estratégicas dos concorrentes) }\end{array}$ \\
\hline Clientes & $\begin{array}{l}\text { Mudança de prioridade; poder; magnitude moderada de concentração de risco. Esse risco é } \\
\text { provavelmente o problema maior para as empresas de seguros comerciais de grande porte }\end{array}$ \\
\hline Projeto & $\begin{array}{l}\text { Falha de pesquisa e desenvolvimento (P\&D); tecnologia da informação (TI); desenvolvimento de } \\
\text { negócios ou Mergers and Acquisitions (M\&A); magnitude alta de risco. As empresas têm longo histórico } \\
\text { de valor que pode ser destruído por fusões e aquisições. Elas também são pequenas investidores em P\&D } \\
\text { e TI. Fusões ou aquisições entram sem contemplar os custos de integração ou prazos, incompatibilidades } \\
\text { culturais, deficiências de reserva etc. Planejamento (particularmente plano de ajuste da relação de perda), } \\
\text { processo não totalmente integrado para os indicadores financeiros internos, benchmarks externos, que } \\
\text { não conseguem atualizar, suscetíveis de otimismo sistemático }\end{array}$ \\
\hline Estagnação & $\begin{array}{l}\text { Volume estável ou em declínio; declínio dos preços; magnitude alta do risco. Esse risco está altamente } \\
\text { relacionado com a gestão da volatilidade do ciclo. As seguradoras têm dificuldade para reimplantar seus } \\
\text { ativos, uma vez que são essencialmente ativos intelectuais com elevado grau de especificidade da tarefa. } \\
\text { As seguradoras também sofrem com atrasos de relatórios extensos e receitas potencialmente inadequadas } \\
\text { e despesas. As seguradoras, para continuar no negócio a preços inadequados, têm necessidade de financiar } \\
\text { seus custos fixos. A resposta organizacional de Flawed planeja ciclos de preços de mercado, incluindo a } \\
\text { manutenção do volume de prêmios e a participação de mercado durante quedas de preços e incentivos de } \\
\text { desempenho impróprios para subscritores. }\end{array}$ \\
\hline
\end{tabular}

Fonte: Adaptado de Mango (2007) e Slywotzky e Drzik (2005).

O Comitê de Assessoramento da Comissão Europeia sobre o Solvency II desenvolveu uma fórmula-padrão que leva a uma margem de solvência exigida, que é destinada a cobrir todos os riscos ao longo de um horizonte de um ano, com probabilidade de 99,5\%. No entanto, as companhias de seguros são encorajadas a desenvolver seus próprios modelos internos para refletir os riscos específicos da empresa com mais precisão. Face ao exposto, é evidente que a medição do fluxo de caixa futuro e sua incerteza tornam-se mais e mais importantes (PLAT, 2011). O estudo de Neves (2010) "Solvência II no Mercado Brasileiro de Seguros: Requerimento de Capital de Solvência", o qual está disponibilizado no sítio eletrônico da Federação Brasileira de Bancos (Febraban) (http://www.febraban.org.br/) prognostica a inserção do mercado brasileiro de seguros às bases do acordo Solvency II.

Quadro 2 - Solvency II: Três pilares

\begin{tabular}{|c|c|c|}
\hline Quantificação de Riscos & Revisão do Supervisor & Disciplina de Mercado \\
\hline Pilar I & Pilar II & Pilar III \\
\hline Requerimentos de capital & Atividades de supervisão & Relato financeiro e divulgação ao público \\
\hline Capital baseado em risco & Controles internos e gestão de riscos & Transparência \\
\hline Capital mínimo & Revisão dos processos & Divulgação \\
\hline
\end{tabular}

Fonte: Neves (2010).

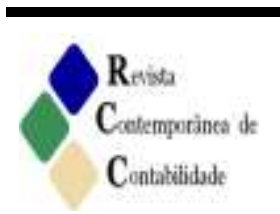


Doff (2008) recomenda uma estrutura mais equilibrada entre os Pilares I, II e III. Isso poderia aumentar a eficiência do quadro Solvency II. Esses pilares deveriam focar e quantificar os riscos, tais como os riscos operacionais e de negócios e os efeitos a longo prazo da decisão estratégica (por exemplo, teste de continuidade).

\subsubsection{Pilar II - Controles Internos e Gestão de Riscos}

Durante muitos anos o setor de seguros exibiu estabilidade a um nível reduzido de insolvências, mas durante as décadas de 1980 e 1990 essa situação mudou drasticamente (ALVES, 1998). Aziz (2013) entende que a instabilidade e o risco das empresas foram agravados pelo avanço da tecnologia, pelo ritmo acelerado de crescimento dos negócios, pela globalização, entre outros fatores que ampliaram a complexidade dos riscos, implicando a capacidade de gerenciamento e suporte ante as mudanças. O referido autor complementa ainda que, no decurso da execução de um negócio, as empresas enfrentam grandes riscos que variam diariamente, incluindo falhas do mecanismo de controle interno, escândalos financeiros, catástrofes ou desastres ambientais, violações de não conformidade e de regulamentação.

Os resquícios de condutas impróprias de notoriedade mundial contribuíram para impulsionar melhorias no processo de supervisão e fiscalização do mercado financeiro (CHAN; SILVA; MARTINS, 2009). Numa tentativa de regulamentações pró-governança, emergiu o novo Acordo da Basileia, ou Basileia II, para acompanhamento de risco operacional em instituições financeiras com o objetivo de desenvolver um sistema mais flexível de adequação de capital, encorajando as instituições financeiras a melhorar sua capacidade de avaliação de riscos (CHAN; SILVA; MARTINS, 2008; CARVALHO; CALDAS, 2008; YANAKA; HOLLAND, 2010). O acordo Basileia II está sustentado em três pilares: Pilar 1 Requerimentos mínimos de capital; Pilar 2 - Processo de revisão de supervisão; Pilar 3 Disciplina de mercado (CHAN; SILVA; MARTINS, 2009; CARVALHO; CALDAS, 2008).

As normas internacionais de instituições superiores de auditoria, The International Standards of Supreme Audit Institutions (ISSAI), publicadas pela International Organizational of Supreme Audit Institutions (INTOSAI), em Viena, Áustria, trazem as diretrizes e normas para o controle interno e definem controle interno como parte integrante da organização, um processo dinâmico integral que está em constante adaptação às mudanças da organização.

O Committee of Sponsoring Organizations of the Treadway Commission (COSO, 2004) define o controle interno como parte integrante do gerenciamento de riscos corporativos, que deve ser conduzido pelo conselho de administração, pela diretoria e pelos empregados. Também deve estar alinhado com as estratégias e ser capaz de identificar qualquer evento com riscos potenciais. Dessa forma, pode garantir o cumprimento dos objetivos estabelecidos pela organização. O conceito de risco para o Solvency II é qualquer alteração no valor positivo ou negativo em relação a um desvio do valor esperado (EUROPÉEN, 2007).

Nas pesquisas que tratam do controle interno e da gestão dos riscos percebe-se unanimidade quanto à compreensão do controle interno dos riscos: "são mecanismos adotados pelas empresas no sentido de minimizar o impacto de riscos de processo e de negócio" (IMONIANA; NOHARA, 2005, p. 38). Os autores destacam que controle é a capacidade de comparar e monitorar o prenunciado com o realizado, comunicar os resultados às unidades responsáveis e, a partir de então, se necessário, estabelecer ações corretivas nos desvios identificados. Para seguradoras e resseguradoras esse conceito se encontra pautado na diretiva do artigo 46 do Solvency II, o qual estabelece que as empresas de seguros e resseguros devem dispor de um compliance interno eficaz, incluindo procedimentos administrativos e contábeis e uma política de comunicação adequada em todos os níveis da organização. 
No Solvency II o controle interno e a gestão de riscos estão sustentados no Pilar II, que discute os princípios básicos do processo de avaliação, a monitorização da eficácia dos sistemas de gestão de risco e controle interno, incluindo a análise da exposição ao risco de cada entidade. A revisão deve incluir o programa de resseguro, os modelos de gestão interna, os riscos e governança corporativos, bem como a possibilidade de exigir, por parte dos supervisores, o capital adicional aos calculados de acordo com os modelos aplicados em casos individuais (LÓPEZ; PÉREZ-FRUCTUOSO; MARTÍN, 2009; EHRLICH, 2012).

Seguradoras e resseguradoras devem atender certos requisitos de solvência a fim de cumprir os compromissos assumidos aos segurados (COMISIÓN..., 2007; FORWARD..., 2012; IAIS, 2012). As empresas de seguros deverão adotar a seguinte política de gestão de riscos: (i) avaliar a exigência de capital total para o perfil do risco; (ii) verificar o cumprimento dos requisitos de capital e as regras para as provisões técnicas; e, (iii) empregar um método para descrever o perfil de risco no cálculo da exigência de capital de solvência (EHRLICH, 2012).

O controle interno e o gerenciamento de risco empresarial (BEASLEY; CLUNE; HERMANSON, 2005; GORDON; LOEBA; TSENG, 2009) fornecem importante fonte de vantagem competitiva para aqueles que podem demonstrar sua capacidade de gerenciá-lo. A Ernst \& Young (2009), líder mundial em auditoria e consultoria, afirma que o sistema de gestão de riscos inclui o modelo interno de capital de solvência, e as seguintes áreas devem estar cobertas: a) subscrição e provisões técnicas; b) gestão de ativo-passivo; c) investimentos em derivativos; d) gestão de risco de liquidez e de concentração; e) gestão de risco operacional; e, f) resseguros e outras técnicas de mitigação de risco.

O processo de avaliação interna de riscos e de solvência é conhecido como a ORSA (Own Risk and Solvency Assessment), que faz parte do processo global de Enterprise Risk Management (ERM) (COSO, 2004; CEIOPS, 2008). Para as seguradoras e resseguradoras, a gestão de risco é o próprio risco de insolvência, e o Pilar II do Solvency II adota medidas prudenciais através de um conjunto de ferramentas destinadas a avaliar de forma contínua e prospectiva a solvência global relacionada com o perfil específico do risco do seguro e da empresa. Essa medida contribui na tomada de decisão estratégica do gestor no cumprimento dos objetivos.

Para tanto, as seguradoras devem alcançar o montante mínimo de capital, Minimum Capital Requirement (MCR), e o capital de solvência, Solvency Capital Requirement (SCR), destinados à absorção de eventuais perdas (CHAN; SILVA; MARTINS, 2008; MARTINS, 2009; NEVES, 2010; GONZÁLEZ et al., 2010). Dessa forma, o Solvency II concebe medidas alinhadas ao planejamento estratégico, as quais são avaliadas continuamente a fim de garantir o cumprimento dos objetivos do MCR e do SCR.

\section{Métodos e Procedimentos de Pesquisa}

A presente pesquisa visa iniciar uma discussão na área de gestão de risco do mercado segurador brasileiro à medida que avança a regulamentação do Solvency II. A investigação é de caráter qualitativo com foco no mercado segurador brasileiro. Dessa forma, este estudo se caracteriza, quanto aos objetivos, como pesquisa descritiva, e quanto aos procedimentos, como documental. A população são as 180 seguradoras brasileiras credenciadas na Susep que publicam suas demonstrações financeiras no sítio eletrônico http://www.susep.gov.br/setoressusep/cgsoa/coaso/demonstracoes-financeiras-intermediarias-e-anuais-2011.

A amostra da pesquisa é não aleatória e intencional. Os pesquisadores investigaram as 30 maiores seguradoras do Brasil, e a base do ranking foi o Ativo Total de cada seguradora no

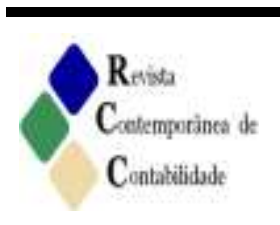


ano de 2011. Optou-se pelo ano de 2011 porque nele há maior número de seguradoras que publicaram seus demonstrativos financeiros. O Quadro 3 demonstra a classificação das empresas pertencentes à amostra da pesquisa e o valor de seu Ativo.

Quadro 3 - Classificação das empresas pertencentes à amostra da pesquisa e o valor de seu Ativo

\begin{tabular}{|c|l|c|c|l|c|}
\hline Classificação & \multicolumn{1}{|c|}{ Seguradora } & \multicolumn{1}{c|}{ Ativo* $^{*}$ Classificação } & \multicolumn{1}{c|}{ Seguradora } & \multicolumn{1}{c|}{ Ativo* } \\
\hline 1 & Bradesco Seg. S.A. & 122.962 .647 & 16 & Icatu Seguros S.A. & 5.476 .843 \\
\hline 3 & Bradesco Vida e Prev. S.A. & 97.534 .646 & 17 & MAPFRE Seg. S.A. & 5.458 .990 \\
\hline 4 & Itaú Vida e Previdência S.A. & 71.455 .482 & 18 & Bradesco Capit. S.A. & 5.265 .790 \\
\hline 5 & Brasilprev Seg. Prev. S.A. & 49.615 .717 & 19 & $\begin{array}{l}\text { Sul América Seg. } \\
\text { Pessoas e Prev. S.A. }\end{array}$ & 4.293 .689 \\
\hline 6 & $\begin{array}{l}\text { Zurich Santander Brasil Seg. } \\
\text { Prev. S.A. }\end{array}$ & 24.639 .426 & 20 & Allianz Seg. S.A. & 4.291 .030 \\
\hline 7 & Itaú Seg. S.A. & 19.663 .776 & 21 & $\begin{array}{l}\text { Cia. Seg. Aliança do } \\
\text { Brasil S.A. }\end{array}$ & 3.591 .806 \\
\hline 8 & Caixa Vida e Prev. S.A. & 16.978 .611 & 22 & $\begin{array}{l}\text { Seg. Líder Consórcios } \\
\text { DPVAT S.A. }\end{array}$ & 3.138 .279 \\
\hline 9 & IRB Brasil RE S.A. & 9.942 .924 & 23 & Paraná Cia Seg. S.A. & 2.912 .146 \\
\hline 10 & $\begin{array}{l}\text { PSBC Vida e Prev. Brasil S.A. } \\
\text { S.A. Seguro Cia Seg. Gerais }\end{array}$ & 9.691 .813 & 24 & Caixa Capitaliz. S.A. & 2.845 .440 \\
\hline 11 & Cia Itaú de Capitaliz. S.A. & 6.953 .035 & 26 & $\begin{array}{l}\text { Metropolitan Life } \\
\text { Seg. Prev. Priv. S.A. }\end{array}$ & 2.744 .039 \\
\hline 12 & $\begin{array}{l}\text { Bradesco AutoRE Cia Seg. } \\
\text { S.A. }\end{array}$ & 6.595 .705 & 27 & HSBC Seg. Br. S.A. & 2.683 .438 \\
\hline 13 & $\begin{array}{l}\text { Sul América Companhia } \\
\text { Nacional Seg. S.A. }\end{array}$ & 5.718 .297 & 28 & $\begin{array}{l}\text { Itaú Seg. Auto } \\
\text { Residência }\end{array}$ & 2.549 .058 \\
\hline 14 & BrasilCapCapitaliz. S.A. & 5.700 .953 & 29 & HDI Seg. S.A. & 2.438 .325 \\
\hline 15 & Caixa Seg. S.A. & 5.592 .504 & 30 & MAPFRE Vida S/A & 2.419 .399 \\
\hline
\end{tabular}

Nota: *Valores expressos em milhares de reais

Fonte: Dados da pesquisa.

A análise de conteúdo é amplamente utilizada na área de negócios desde a década de 1980 (JAUCH; OSBORN; MARTIN, 1980; MOLOI, 2016). A análise de conteúdo empregou um cronograma de análise para extrair as informações relevantes de casos publicados das notas explicativas no período de 2011 e 2012. As informações dos casos foram codificadas em um cronograma de análise de conteúdo. Desta forma, apenas as informações específicas foram codificadas. Os dados do estudo foram coletados por meio de pesquisa documental das notas explicativas publicadas nos anos de 2011 e 2012, conforme disponibilização de acesso no referido site. Dada a complexidade do tema e as particularidades das informações nas notas explicativas, cada empresa foi analisada individualmente. Os pesquisadores primeiramente selecionaram os textos das notas explicativas. Esse procedimento teve como base a pesquisa por palavras-chave, como: "Avaliação de riscos", "Capital mínimo requerido", "Controles internos".

A partir das notas explicativas do período de 2011 e 2012 das seguradoras brasileiras, foi realizada uma análise da evidenciação e documentação tomando como base os critérios e a metodologia de cada seguradora quanto aos níveis de gestão de risco. Os dados tomaram como base as 13 perspectivas inovadoras de gestão de risco de Taylor (2012). Após a conclusão da primeira etapa, iniciou-se o processo de enquadramento dos textos selecionados nas 13 Perspectivas do Solvency II, baseadas no estudo de Taylor (2012), conforme demonstra o Quadro 4. 
Quadro 4 - Perspectivas Solvency II

\begin{tabular}{|c|c|}
\hline Perspectiva & Descrição \\
\hline 1 & $\begin{array}{l}\text { A avaliação do risco e solvência deve incluir o perfil de risco específico; os limites aprovados de tolerância } \\
\text { de risco; a estratégia de negócios da empresa; requisitos relativos às provisões técnicas, conforme previsto } \\
\text { no Capítulo VI, Seção 2; requisitos de capital, previstos no Capítulo VI, Seções } 4 \text { e 5; e, requisitos de } \\
\text { capital de solvência estabelecido no artigo 101, calculado pela fórmula-padrão, em conformidade com o } \\
\text { Capítulo VI, Seção 4, Subseção } 2\end{array}$ \\
\hline 2 & $\begin{array}{l}\text { Identificação e avaliação correta dos riscos que as empresas enfrentam a curto e a longo prazo. As empresas } \\
\text { devem demonstrar os métodos utilizados nessa avaliação }\end{array}$ \\
\hline 3 & $\begin{array}{l}\text { A avaliação de risco e solvência deve ser parte integrante da estratégia de negócio e deve ser levada em } \\
\text { consideração como base contínua nas decisões estratégicas da empresa }\end{array}$ \\
\hline 4 & As empresas devem efetuar frequentemente a avaliação de risco e solvência \\
\hline 5 & $\begin{array}{l}\text { As empresas devem informar às autoridades de supervisão os resultados de cada avaliação de risco e } \\
\text { solvência }\end{array}$ \\
\hline 6 & $\begin{array}{l}\text { O requisito de capital de solvência deve ser ajustado somente em conformidade com os artigos 37, 231- } \\
233 \text { e } 238\end{array}$ \\
\hline 7 & A organização da empresa deve conter um sistema de alerta precoce de riscos \\
\hline 8 & Competência e idoneidade das empresas na avaliação do risco e solvência \\
\hline 9 & Auditoria interna na função atuarial \\
\hline 10 & Função da auditoria no diálogo entre a governança e processos de supervisão \\
\hline 11 & $\begin{array}{l}\text { Funções dos processos de supervisão: avaliação e revisão de todos os processos para o cumprimento das } \\
\text { leis e normas administrativas; acesso e revisão do sistema de governança; avaliação de todos os riscos e } \\
\text { capacidade de avaliação da empresa }\end{array}$ \\
\hline 12 & $\begin{array}{l}\text { Perfil da empresa quanto a apetite ao risco e a tolerância ao risco. Definição de apetite ao risco: quantidade } \\
\text { e tipo de risco que a organização está disposta a buscar ou manter. Quantidade e tipo de risco que a } \\
\text { organização está preparada para buscar, aceitar ou tolerar }\end{array}$ \\
\hline 13 & Utilização de controles internos para minimização de riscos \\
\hline
\end{tabular}

Fonte: Adaptado de Taylor (2012).

A terceira fase dá-se por meio da análise de conteúdo dos textos selecionados das notas explicativas e seu enquadramento nas 13 Perspectivas de Taylor (2012). A natureza da análise dos dados coletados nesta pesquisa é qualitativa. Bardin (1977) relaciona as possibilidades de uso da análise de conteúdo em entrevistas ou depoimentos, escritos em jornais, livros ou textos, como também em imagens de filmes, desenhos, pinturas, cartazes, televisão e toda comunicação não verbal e outras expressões culturais.

\section{Análise dos Dados}

\subsection{Avaliação de Risco e Solvência}

A análise dos dados é inicialmente concebida (Quadro 5) a partir da segunda fase da pesquisa, a qual expõe, conforme Taylor (2012), o enquadramento dos textos selecionados das notas explicativas das seguradoras na Perspectiva 1 do Solvency II.

Para melhor compreensão da Perspectiva 1, o Quadro 5 foi estruturado com cinco divisões: perfil de risco específico, limites de tolerância de risco, estratégia de negócios, provisões técnicas e requisitos de capital de solvência.

A partir dessa estrutura vislumbra-se que doze seguradoras evidenciam em suas notas explicativas o perfil de risco específico. A Zurich Santander Brasil Seg. Prev. S. A. destacouse nesse quesito. A seguir, o texto extraído de suas publicações:

São analisados entre outros os seguintes riscos: Risco de Crédito; Risco de Subscrição; Risco Atuarial; Risco de Compliance; Risco de Reputação; Risco de Mercado. No que concerne aos limites de tolerância de risco, a Caixa Capitalização S. A. afirma o seguinte: "A estrutura de limites é estabelecida sobre métricas e limites de risco de mercado. (a) Valor em Risco (VaR - Value at Risk); (b) Perdas em 
Cenários de Estresse (Teste de Estresse); e (c) Sensibilidade (DV01 - Delta Variation Risk).

Quadro 5 - Enquadramento das Seguradoras na Perspectiva 1

\begin{tabular}{|c|c|c|c|c|}
\hline $\begin{array}{c}\text { Perfil de risco } \\
\text { específico }\end{array}$ & $\begin{array}{c}\text { Limites de tolerância } \\
\text { de risco }\end{array}$ & $\begin{array}{c}\begin{array}{c}\text { Estratégia de } \\
\text { negócios }\end{array} \\
\end{array}$ & Provisões técnicas & $\begin{array}{c}\text { Requisitos capital de } \\
\text { solvência }\end{array}$ \\
\hline $\begin{array}{l}\text { Itaú Vida e } \\
\text { Previdência S.A. } \\
\text { Zurich Santander } \\
\text { Brasil Seg. Prev. } \\
\text { S.A. } \\
\text { Itaú Seg. S.A. } \\
\text { Caixa Vida e Prev. } \\
\text { S.A. } \\
\text { HSBC Vida e Prev. } \\
\text { Brasil S.A. } \\
\text { Sul América } \\
\text { Companhia Nacional } \\
\text { Seg. S.A. } \\
\text { Brasil Cap Capitaliz. } \\
\text { S.A. } \\
\text { Caixa Seg. S.A. } \\
\text { Icatu Seguros AS } \\
\text { Sul América Seg. } \\
\text { Pessoas e Prev. S.A. } \\
\text { Allianz Seg. S.A. } \\
\text { Paraná Cia Seg. S.A. }\end{array}$ & $\begin{array}{l}\text { Bradesco Seg. S.A. } \\
\text { Bradesco Vida e Prev. } \\
\text { S.A. } \\
\text { Brasilprev Seg. Prev. } \\
\text { S.A. } \\
\text { Zurich Santander } \\
\text { Brasil Seg. Prev. S.A. } \\
\text { Itaú Seg. S.A. } \\
\text { Caixa Vida e Prev. } \\
\text { S.A. } \\
\text { IRB Brasil RE S.A. } \\
\text { HSBC Vida e Prev. } \\
\text { Brasil S.A. } \\
\text { Porto Seguro Cia Seg. } \\
\text { Gerais S.A. } \\
\text { Cia Itaú de Capitaliz. } \\
\text { S.A. } \\
\text { Sul América } \\
\text { Companhia Nacional } \\
\text { Seg. S.A. } \\
\text { Brasil Cap Capitaliz. } \\
\text { S.A. } \\
\text { Caixa Seg. S.A. } \\
\text { Icatu Seguros AS } \\
\text { MAPFRE Seg. S.A. } \\
\text { Sul América Seg. } \\
\text { Pessoas e Prev. S.A. } \\
\text { Allianz Seg. S.A. } \\
\text { Cia Seg. Aliança do } \\
\text { Brasil S.A. } \\
\text { Seg Líder Consórcios } \\
\text { DPVAT S.A. } \\
\text { Paraná Cia Seg. S.A. } \\
\text { Caixa Capitaliz. S.A. } \\
\text { Metropolitan Life Seg. } \\
\text { Prev. Priv. S.A. } \\
\text { HSBC Seg. Br. S.A. } \\
\text { Itaú Seg. Auto } \\
\text { Residência. } \\
\text { HDI Seg. S.A. } \\
\text { MAPFRE Vida S.A. }\end{array}$ & $\begin{array}{l}\text { Zurich Santander } \\
\text { Brasil Seg. Prev. } \\
\text { S.A. } \\
\text { Caixa Vida e Prev. } \\
\text { S.A. } \\
\text { Icatu Seguros S.A. } \\
\text { MAPFRE Seg. S.A. }\end{array}$ & $\begin{array}{l}\text { Itaú Vida e } \\
\text { Previdência S.A. } \\
\text { Zurich Santander } \\
\text { Brasil Seg. Prev. } \\
\text { S.A. } \\
\text { HSBC Vida e Prev. } \\
\text { Brasil S.A. } \\
\text { Bradesco AutoRE } \\
\text { Cia Seg. S.A. } \\
\text { Sul América } \\
\text { Companhia Nacional } \\
\text { Seg. S.A. } \\
\text { Brasil Cap Capitaliz. } \\
\text { S.A. } \\
\text { Caixa Seg. S.A. } \\
\text { Icatu Seguros AS } \\
\text { Sul América Seg. } \\
\text { Pessoas e Prev. S.A. } \\
\text { Cia Seg. Aliança do } \\
\text { Brasil S.A. } \\
\text { Seg Líder } \\
\text { Consórcios DPVAT } \\
\text { S.A. } \\
\text { Paraná Cia Seg. S.A. } \\
\text { Metropolitan Life } \\
\text { Seg. Prev. Priv. S.A. } \\
\text { Safra Vida Prev. } \\
\text { S.A. } \\
\text { Itaú Seg. Auto } \\
\text { Residência. } \\
\text { HDI Seg. S.A. } \\
\text { MAPFRE Vida S.A. }\end{array}$ & $\begin{array}{l}\text { Bradesco Seg. S.A. } \\
\text { Bradesco Vida e Prev. } \\
\text { S.A. } \\
\text { Brasilprev Seg. Prev. } \\
\text { S.A. } \\
\text { Zurich Santander Brasil } \\
\text { Seg. Prev. S.A. } \\
\text { Itaú Seg. S.A. } \\
\text { HSBC Vida e Prev. } \\
\text { Brasil S.A. } \\
\text { Porto Seguro Cia Seg. } \\
\text { Gerais S.A. } \\
\text { Bradesco AutoRE Cia } \\
\text { Seg. S.A. } \\
\text { Brasil Cap Capitaliz. } \\
\text { S.A. } \\
\text { Caixa Seg. S.A. } \\
\text { Icatu Seguros AS } \\
\text { Allianz Seg. S.A. } \\
\text { Cia Seg. Aliança do } \\
\text { Brasil S.A. } \\
\text { Caixa Capitaliz. S.A. } \\
\text { Metropolitan Life Seg. } \\
\text { Prev. Priv. S.A. } \\
\text { Safra Vida Prev. S.A. } \\
\text { Itaú Seg. Auto } \\
\text { Residência. } \\
\text { HDI Seg. S.A. } \\
\text { MAPFRE Vida S.A. }\end{array}$ \\
\hline
\end{tabular}

Fonte: Dados da pesquisa.

O perfil de risco das seguradoras que evidenciam o perfil de risco específico leva em conta o perfil de risco específico da empresa e os limites de tolerância ao risco aprovados, que é uma das diretrizes do Solvency II. Quanto à estratégia de negócios, apenas quatro seguradoras discriminam sua estratégia em relação ao gerenciamento de riscos. A Caixa Vida e Previdência S. A. publica o seguinte:

A estrutura do Processo de Gerenciamento de Riscos da Companhia permite que os riscos de Seguro, Crédito, Liquidez, Mercado e Operacional sejam efetivamente identificados, avaliados, monitorados, controlados e mitigados de modo unificado. $\mathrm{O}$ gerenciamento de todos os riscos inerentes às atividades de modo integrado é abordado, dentro de um processo, apoiado em uma estrutura de Controles Internos e Compliance. 
O grande desafio estratégico que confronta todas as instituições seguradoras é a cultura de risco (JEDNAK; JEDNAK, 2013). A cultura de gestão de risco dentro de uma organização pode afetar a coleta e o processamento de dados de perda (BRYCE et al., 2016). As diretrizes do Solvency II deixam claro que as companhias de seguros devem realizar a sua própria avaliação de risco e solvência, incluindo as necessidades de solvência global, tendo em conta o seu perfil de risco específico, bem como os limites de tolerância de risco aprovados e estratégias de negócio bem definidas (FLORYSZCZAK; LE COURTOIS; MAJRI, 2014). Para as provisões técnicas, a seguradora Metropolitan Life Seguros e Previdência Privada S. A. destacou em sua publicação: "De acordo com a Administração, as provisões para riscos de crédito são calculadas conforme: (i) a provisão sobre prêmios diretos a receber; e (ii) a provisão para operações a receber". E, por fim, quanto aos requisitos de capital de solvência, a Bradesco Vida e Previdência S.A. evidenciou da seguinte forma:

[...] acompanha de maneira permanente os limites requeridos (margem de solvência, capital mínimo requerido e capital adicional) pelo respectivo órgão regulador. Os processos são continuamente reavaliados e os testes de aderência, para aferir a efetividade dos controles existentes, regularmente aplicados, em conformidade com os principais frameworks de controles, como o COSO (Committee of Sponsoring Organizations of the Treadway Commission) e o COBIT (Control Objectives for Information and Related Technology), que abrangem, respectivamente, aspectos de negócio e tecnologia.

A diretriz referente a provisões técnicas do Solvency II aconselha que a empresa deve assegurar a função atuarial fornecendo informações sobre a conformidade com os requisitos para o cálculo das provisões técnicas e os riscos decorrentes deste cálculo. As informações pertinentes aos riscos ligados às provisões técnicas devem ser comunicadas ao órgão de direção, ou qualquer outra pessoa para quem a informação seja relevante. Além dos riscos ligados às provisões técnicas, riscos de mercado, riscos de liquidez, riscos operacionais, entre outros, devem constar no relatório de provisões técnicas (TAYLOR, 2012). Já o capital de solvência apresenta a avaliação dos riscos considerados do modelo de negócio (TAYLOR, 2012).

\subsection{Métodos Utilizados na Avaliação do Risco}

O Quadro 6 apresenta a Perspectiva 2 dividida em Identificação e avaliação correta dos riscos e Métodos utilizados, no âmbito da identificação e da avaliação dos riscos. A Sul América Seguros de Pessoas e Previdência S.A. reporta-se da seguinte forma: "Para controle, avaliação e acompanhamento do risco de mercado das carteiras, são utilizados o $V a R$ Paramétrico e o stress testing". Conforme Plat (2011), sobre passivos na base de valor contábil, a exposição da Porto Seguro Cia de Seguros Gerais é:

\footnotetext{
Os principais segmentos de gestão de riscos de seguros estão estruturados da seguinte forma: Automóveis particulares e comerciais; Vida sem cobertura por sobrevivência; Seguros patrimoniais, responsabilidade civil e de crédito; Transportes. Para mitigação do risco de taxas de juros gerado a partir das garantias mínimas dos planos tradicionais, a Companhia faz a gestão do fluxo de ativos e passivos ALM - Asset Liability Management.
}

Essas informações convalidam também os achados de Reij (2008), o qual foca a relação entre as técnicas de gestão de risco nas seguradoras holandesas para reduzir o risco da taxa de juros. Esse procedimento está de acordo com as premissas do Solvency II.

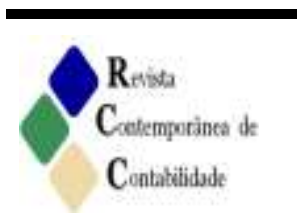




\begin{tabular}{|c|c|c|c|}
\hline \multicolumn{2}{|c|}{ Identificação e avaliação correta dos riscos } & \multicolumn{2}{|c|}{ Métodos utilizados } \\
\hline $\begin{array}{l}\text { Bradesco Seg. S.A. } \\
\text { Brasilprev Seg. Prev. S. } \\
\text { A. } \\
\text { Zurich Santander Brasil } \\
\text { Seg. Prev. S.A. } \\
\text { Itaú Seg. S.A. } \\
\text { Caixa Vida e Prev. S.A. } \\
\text { IRB Brasil RE S.A. } \\
\text { HSBC Vida e Prev. } \\
\text { Brasil S.A. } \\
\text { Porto Seguro Cia Seg. } \\
\text { Gerais S.A. } \\
\text { Cia Itaú de Capitaliz. S.A. } \\
\text { Bradesco AutoRE Cia } \\
\text { Seg. S.A. } \\
\text { Brasil Cap Capitaliz. } \\
\text { S.A. } \\
\text { Caixa Seg. S.A. } \\
\text { MAPFRE Seg. S.A. }\end{array}$ & $\begin{array}{l}\text { Bradesco Capit. S.A. } \\
\text { Sul América Seg. Pessoas e } \\
\text { Prev. S.A. } \\
\text { Allianz Seg. S.A. } \\
\text { Cia Seg. Aliança do Brasil } \\
\text { S.A. } \\
\text { Seg Líder Consórcios DPVAT } \\
\text { S.A. } \\
\text { Paraná Cia Seg. S.A. } \\
\text { Caixa Capitaliz. S.A. } \\
\text { Metropolitan Life Seg. Prev. } \\
\text { Priv. S.A. } \\
\text { HSBC Seg. Br. S.A. } \\
\text { Safra Vida Prev. S.A. } \\
\text { Itaú Seg. Auto Residência } \\
\text { MAPFRE Vida S.A. }\end{array}$ & $\begin{array}{l}\text { Bradesco Seg. S.A. } \\
\text { Zurich Santander Brasil Seg. } \\
\text { Prev. S.A. } \\
\text { Itaú Seg. S.A. } \\
\text { Caixa Vida e Prev. S.A. } \\
\text { IRB Brasil RE S.A. } \\
\text { HSBC Vida e Prev. Brasil } \\
\text { S.A. } \\
\text { Porto Seguro Cia Seg. Gerais } \\
\text { S.A. } \\
\text { Bradesco AutoRE Cia Seg. } \\
\text { S.A. } \\
\text { Brasil Cap Capitaliz. S.A. } \\
\text { Caixa Seg. S.A. } \\
\text { MAPFRE Seg. S.A. }\end{array}$ & $\begin{array}{l}\text { Bradesco Capit. S.A. } \\
\text { Sul América Seg. Pessoas } \\
\text { e Prev. S.A. } \\
\text { Allianz Seg. S.A. } \\
\text { Seg Líder Consórcios } \\
\text { DPVAT S.A. } \\
\text { Paraná Cia Seg. S.A. } \\
\text { Caixa Capitaliz. S.A. } \\
\text { Metropolitan Life Seg. } \\
\text { Prev. Priv. S.A. } \\
\text { HSBC Seg. Br. S.A. } \\
\text { Safra Vida Prev. S.A. } \\
\text { Itaú Seg. Auto Residência } \\
\text { MAPFRE Vida S.A. }\end{array}$ \\
\hline
\end{tabular}

Fonte: Dados da pesquisa.

$\mathrm{Na}$ segunda divisão, aquisição e manutenção de ativos para geração de adequado retorno, a Companhia de Seguros Aliança do Brasil e a Metropolitan Life Seguros e Previdência Privada S.A. apresentam o seguinte:

\begin{abstract}
Para a projeção do montante dos sinistros futuros referentes aos riscos vigentes na data-base de cálculo, é utilizado modelo estatístico de regressão. E, para a projeção da PPNG futura e das despesas de comercialização diferida futura, é aplicado o diferimento pelo prazo de vigência do risco (Companhia de Seguros Aliança do Brasil). Anualmente, o teste de adequação do passivo é efetuado. Utilizam-se as estimativas dos fluxos de caixa futuros, sinistros e despesas administrativas e incrementais a de liquidação de sinistros. Os fluxos de caixa futuros são trazidos a valor presente, conforme determinado pela Susep. O monitoramento é feito através (sic) do casamento entre ativos e passivos (Asset and Liability Management) (Metropolitan Life seguros e Previdência Privada S.A.).
\end{abstract}

\title{
4.3 Avaliação de Risco e Solvência na Estratégia de Negócio
}

A Perspectiva 3 concebe que a avaliação de risco e solvência deve ser parte integrante da estratégia de negócio. Para tanto, identificaram-se as seguintes seguradoras, que avaliam o risco com base nos fundamentos da estratégia da empresa: Itaú Vida e Previdência S.A.; Itaú Seg. S.A.; Caixa Vida e Prev. S.A.; HSBC Vida e Prev. Brasil S.A.; Bradesco AutoRE Cia Seg. S.A.; Icatu Seguros S.A.; Sul América Seg. Pessoas e Prev. S.A.; Allianz Seg. S.A.; Cia Seg. Aliança do Brasil S.A.; Paraná Cia Seg. S.A.; Caixa Capitaliz. S.A.; Metropolitan Life Seg. Prev. Priv. S.A.; HSBC Seg. Br. S.A.; MAPFRE Vida S.A.

Em destaque, as notas publicadas pela Icatu Seguros S.A. e pela MAPFRE Vida S.A. (antiga MAPFRE Vera Cruz Vida e Previdência S.A.), respectivamente, utilizam "[...] como metodologia o COSO - Committee of Sponsoring Organizations of the Treadway Commission e o Enterprise Risk Management (ERM), que é um processo com foco nos controles internos, executado pela Diretoria de Governança e aplicado na determinação de estratégias por toda a Sociedade". "O processo de gerenciamento de riscos conta com a participação de todas as camadas contempladas pelo escopo de governança corporativa que abrange desde a Alta Administração até as diversas áreas de negócios e produtos na identificação, tratamento e 
monitoramento desses riscos".

Esta diretriz de avaliação de risco e solvência é um componente-chave na avaliação de estratégias operacionais de mitigação de risco. Nesse sentido, Liebwein (2006) fortalece esta perspectiva por meio de um estudo de caso em que os modelos internos de risco devem ser utilizados não só para cumprir os requisitos de regulamentos, mas também apresentar modelos que promovam processos de gestão de risco. Além disso, a avaliação de risco e solvência na estratégia de negócio reflete a paisagem de risco da companhia de seguros com mais precisão do que qualquer outra abordagem, possibilitando o cumprimento dos requisitos regulamentares e informações relevantes e úteis para as partes interessadas de uma companhia de seguros.

\title{
4.4 Frequência da Avaliação do Risco
}

Dentro da Perspectiva 4, as empresas devem efetuar frequentemente a avaliação de risco e solvência. Constataram-se dezessete seguradoras que enunciaram a frequência da referida avaliação. No entanto, não se pode afirmar a média de regularidade dessas avaliações, pois em várias delas indicou-se avaliação anual, e em outras, avaliação até mesmo trimestral. $\mathrm{Na}$ sequência, alguns destaques:

Anualmente a Zurich Santander Brasil Seguros e Previdência S.A. realiza, além do Teste de Adequação do Passivo (nota 4.1), criteriosas avaliações atuariais de toda a sua carteira vigente para verificar a solvência ou necessidade de reservas complementares. Através das ferramentas de controles SOX, bem como as atividades pertinentes ao Plano de Continuidade aos Negócios, continuam sendo prestadas pelo banco através (sic) de um SLA acordado entre as duas companhias (ZURICH SANTANDER BRASIL SEG. PREV. S.A.).

O exposto acima é contrário à afirmação de Plat (2011), para quem as seguradoras não se baseiam em seus riscos reais para o cálculo do capital de solvência.

\begin{abstract}
A Companhia avalia trimestralmente os seus riscos e a sua infraestrutura de controles internos é formada por Comitês que avaliam todos os riscos (subscrição, crédito, mercado, liquidez, operacional e legal), define os limites de tolerância e elabora planos de mitigação entre outras atribuições. Em conformidade com os principais frameworks de controle, como o COSO - Committee of Sponsoring Organizations of the Treadway Commission - e o COBIT - Control Objectives for Information and Related Technology (Bradesco Seguros S.A.).
\end{abstract}

\subsection{Comunicação às Autoridades de Supervisão}

De acordo com a Perspectiva 5, apenas as seguradoras Caixa Seguradora S.A. e Safra Vida e Previdência S.A. apresentam em suas notas explicativas a informação da comunicação às autoridades de supervisão dos resultados de cada avaliação de risco e solvência. Entretanto, entende-se que todas as seguradoras cadastradas na Susep informam as autoridades competentes, caso contrário estariam em processo de intervenção.

A grande maioria das seguradoras contraria a perspectiva de comunicação às autoridades de supervisão, contrariando o modelo de risco do Solvency II que preconiza que o modelo de risco da companhia de seguro ajuda a comunicar os resultados associados como potencias agregadores de valor (LIEBWEIN, 2006). 


\subsection{Requisito de Capital de Solvência}

O requisito de capital de solvência deve ser ajustado em conformidade com os artigos 37, 231-233 e 238, Perspectiva 6, desta pesquisa. Apenas dezesseis seguradoras apresentam nas notas explicativas de 2011 e 2012 detalhes sobre o requisito de capital de solvência de acordo com os artigos 37, 231-233 e 238 e regulamentos da Susep, definido na Resolução CNSP no 8 , de 1989, com seu Art. 2º sendo alterado pela Resolução CNSP no 055, de 2001.

Segue a lista dessas seguradoras: Bradesco Seg. S.A., Bradesco Vida e Prev. S.A., Itaú Vida e Previdência S.A., Brasilprev Seg. Prev. S.A., Zurich Santander Brasil Seg. Prev. S.A., Itaú Seg. S.A., Bradesco AutoRE Cia. Seg. S.A., MAPFRE Seg. S.A., Bradesco Capit. S.A., Sul América Seg. Pessoas e Prev. S.A., Cia Seg. Aliança do Brasil S.A., Metropolitan Life Seg. Prev. Priv. S.A., HSBC Seg. Br. S.A., Safra Vida Prev. S.A., Itaú Seg. Auto Residência e HDI Seg. S.A. A seguir, a exposição da Bradesco Seguros S.A.:

No que se refere à solvência, o Grupo está em compliance com o disposto nas Resoluções nos. 222/10, 227/10 e 228/10, do CNSP, e com o disposto na Resolução Normativa no. 246/11, da Agência Nacional de Saúde. A Companhia apura o Capital Mínimo Requerido (CMR) em conformidade com as regulamentações emitidas pelo CNSP e SUSEP, utilizando as tabelas de fatores suavizadas em função de possuir modelo interno. A Companhia avalia trimestralmente os seus riscos e a sua infraestrutura de controles internos é formada por Comitês que avaliam todos os riscos (subscrição, crédito, mercado, liquidez, operacional e legal), define os limites de tolerância e elabora planos de mitigação entre outras atribuições. Em conformidade com os principais frameworks de controles, como o COSO e o COBIT.

O Itaú Seguros S.A. evidencia os fatores de risco e solvência, no entanto adiciona a informação que é parte integrante de um conglomerado econômico financeiro:

No Itaú Unibanco Holding S.A. os fatores de risco e solvência são controlados e geridos de forma consolidada. Desta forma, os instrumentos financeiros da ITAÚ VIDA, subsidiária integral do ITAÚ UNIBANCO HOLDING, são parte integrante da Carteira Trading ou Banking do conglomerado econômico-financeiro, conforme definido pela Resolução no 3.464/07 e na Circular nº 3.354/07 do BACEN e no Novo Acordo de Capitais - Basileia II.

Eling e Pankoke (2014) explicam, através de uma regressão com 85 seguradoras da Alemanha, Suíça, Áustria e Luxemburgo, que a gestão de risco é um tópico relativamente novo na prática e nos estudos da academia. Em especial, o fenômeno pelos requisitos de capital de solvência. Os pesquisadores concluem que com a introdução do Solvency II, a gestão ativa das atividades das seguradoras se tornará cada vez mais importante, uma vez que as seguradoras terão de ter capital próprio mais elevado para as carteiras de negócios. A pesquisa ainda ilustra que apenas $23 \%$ das seguradoras evidenciam o risco de reserva como requisito de capital de solvência.

\subsection{Sistema de Alerta Precoce de Riscos}

De acordo com a Perspectiva 7, apenas duas seguradoras, Bradesco Vida e Prev. S.A. e Mapfre Vida S.A., apregoam estar em conformidade com a Perspectiva de que a organização da empresa deve conter um sistema de alerta precoce de riscos. Um sistema de alerta que serve para intervenções dos supervisores. A Mapfre Vida S.A. (antiga Mapfre Vera Cruz Vida e Previdência S.A.) revela o seguinte: "adota políticas rígidas de controle e estratégias previamente estabelecidas e aprovadas pelo Comitê Financeiro e pelo Conselho de Administração, as operações são controladas com as ferramentas Stress Testing e Value At 
Risk”.

A investigação de Liebwein, (2006) assinala que a maioria das seguradoras europeias adota sistema de alerta precoce para a margem de solvência. Quando os níveis de solvência caem abaixo do nível preconizado, medidas de supervisão são tomadas. Estas medidas refletem basicamente o capital necessário para atingir um determinado nível de segurança da companhia.

\title{
4.8 Competência e Idoneidade
}

A Perspectiva 8 é sobre a competência e a idoneidade das empresas na avaliação de risco e solvência. As seguradoras Itaú Vida e Previdência S.A., Itaú Seg. S.A., Bradesco Capit. S.A., Seg. Líder Consórcios DPVAT S.A., Metropolitan Life Seg. Prev. Priv. S.A., Itaú Seg. Auto Residência, e HDI Seg. S.A. explicitam de diferentes formas sua competência e idoneidade na avaliação dos riscos. Como destaque, a Seguradora Líder - DPVAT - diz que possui " [...] uma estrutura de compliance e a figura dos agentes de compliance, a fim de adequar as suas atividades às determinações dos órgãos regulamentadores e fiscalizadores, através de uma sólida cultura de controles internos, elevados padrões de integridade e excelência ética e aderência à legislação". A Metropolitan Life Seguros e Previdência Privada S.A. tem a seguinte estrutura:

\begin{abstract}
Possui um comitê que desenvolve suas atividades com base em plano de trabalho do seu regimento interno, que incluiu: (i) entrevistas aos gestores; (ii) acompanhamento e monitoração dos trabalhos, controles internos, gestão de riscos e função de compliance; (iii) avaliação do escopo e desempenho da auditoria interna; (iv) avaliação do escopo, desempenho e independência dos auditores independentes; e (v) avaliação da estrutura e funcionamento dos sistemas de controles internos, compliance e de gerenciamento de riscos.
\end{abstract}

Esta preocupação das seguradoras citadas vem ao encontro da diretiva que prevê que a função atuarial será exercida por pessoas com conhecimento de matemática atuarial e financeira envolvidas com grupos de trabalho que possam demonstrar a sua experiência relevante com mecanismo prudências à escala e à complexidade dos riscos inerentes à atividade da seguradora (Diretiva 2009/138 / CE, artigo 48, n² 2) (WILLIAMS et al., 2015).

\subsection{Auditoria Interna na Função Atuarial}

$\mathrm{Na}$ Perspectiva 9, as seguradoras precisam dispor de auditoria interna na função atuarial. Apenas sete seguradoras se encaixam nesta Perspectiva: Itaú Vida e Previdência S.A., Brasilprev Seg. Prev. S.A., Mapfre Seg. S.A., Allianz Seg. S.A., Paraná Cia Seg. S.A., Caixa Capitaliz. S.A., Mapfre Vida S.A. A seguradora Mapfre Vida S.A. (antiga Mapfre Vera Cruz Vida e Previdência S.A.) revela:

Constituído como órgão de apoio vinculado ao Comitê Executivo, no âmbito da estrutura de governança corporativa do Grupo Segurador Banco do Brasil e Mapfre, adiante designado apenas Grupo, tendo como objetivo avaliar e acompanhar, bem como auxiliar a alta direção no processo de avaliação e decisão quanto aos riscos corporativos e controles internos, de acordo com as diretrizes estabelecidas pelo Conselho de Administração.

A função da auditoria interna é fornecer garantia, independentemente de os processos de gestão de risco, governança e controle interno da seguradora estejam operando de forma 
eficaz. A função da auditoria interna deve ser de trabalhar proativamente para melhorar a colaboração efetiva, as responsabilidades claras e a aceitação de pares com a Função Atuarial. A função atuarial se concentra no processo atuarial. Dependendo do tamanho e da maturidade da Seguradora, o foco no conteúdo atuarial pode ser conduzido pela função de auditoria interna (WILLIAMS et al., 2015).

\subsection{Auditoria no Diálogo entre a Governança e a Supervisão}

A Perspectiva 10 concebe a função da auditoria no diálogo entre a governança e os processos de supervisão. As dez seguradoras que estão enquadradas nesta perspectiva são: Bradesco Vida e Prev. S.A., Cia Itaú de Capitaliz. S.A., Bradesco AutoRE Cia Seg. S.A., Icatu Seguros S.A., Mapfre Seg. S.A., Bradesco Capit. S.A., Allianz Seg. S.A., Cia Seg. Aliança do Brasil S.A., Seg. Líder Consórcios DPVAT S.A. e Metropolitan Life Seg. Prev. Priv. S.A.

A Seguradora Líder dos Consórcios DPVAT e Bradesco Vida e Previdência S.A. têm as seguintes afirmações, respectivamente: "o Comitê de Auditoria, desde a sua instalação, realiza reuniões mensais com diversas áreas operacionais da Companhia, incluindo a Diretoria, Auditoria Interna e Controles Internos, bem como com os Auditores Externos e com o Conselho Fiscal". "O grupo possui Comitês formalmente instituídos que suportam as operações e conferem transparência na busca constante dos mais elevados padrões de integridade e comportamento ético".

Esta discussão é fortalecida com os resultados da investigação de De Haan e Kakes, (2010) que pesquisaram, a partir de um conjunto de dados de 350 seguradoras holandesas, as principais linhas de negócios durante o período pré-Solvency II, entre 1995-2005. Entre os diferentes achados dos pesquisadores está a importância da avaliação de risco através do diálogo entre a auditoria e a governança das seguradoras.

\subsection{Funções dos Processos de Supervisão}

As seguradoras da Perspectiva 11 apresentam-se conforme o Quadro 7.

Quadro 7 - Enquadramento das Seguradoras na Perspectiva 11

\begin{tabular}{|c|c|c|}
\hline $\begin{array}{l}\text { Funções dos processos de supervisão: } \\
\text { avaliação e revisão de todos os processos } \\
\text { para o cumprimento das leis e normas } \\
\text { administrativas }\end{array}$ & $\begin{array}{c}\text { Acesso e revisão do } \\
\text { sistema de governança }\end{array}$ & $\begin{array}{l}\text { Avaliação de todos os riscos e } \\
\text { a capacidade de avaliação da } \\
\text { empresa }\end{array}$ \\
\hline $\begin{array}{l}\text { Itaú Vida e Previdência S.A. } \\
\text { Cia Itaú de Capitaliz. S.A. } \\
\text { Brasil Cap Capitaliz. S.A. } \\
\text { Caixa Seg. S.A. } \\
\text { Icatu Seguros AS } \\
\text { Mapfre Seg. S.A. } \\
\text { Bradesco Capit. S.A. } \\
\text { Sul América Seg. Pessoas e Prev. S.A. } \\
\text { Cia Seg. Aliança do Brasil S.A. } \\
\text { Paraná Cia Seg. S.A. } \\
\text { Metropolitan Life Seg. Prev. Priv. S.A. } \\
\text { HSBC Seg. Br. S.A. } \\
\text { Itaú Seg. Auto Residência } \\
\text { HDI Seg. S.A. }\end{array}$ & $\begin{array}{l}\text { Bradesco Vida e Prev. S.A. } \\
\text { Cia Itaú de Capitaliz. S.A. } \\
\text { Caixa Seg. S.A. } \\
\text { Bradesco Capit. S.A. }\end{array}$ & $\begin{array}{l}\text { Bradesco Seg. S.A. } \\
\text { Cia Itaú de Capitaliz. S.A. } \\
\text { Caixa Seg. S.A. } \\
\text { Icatu Seguros AS } \\
\text { Mapfre Seg. S.A. } \\
\text { Bradesco Capit. S.A. } \\
\text { Allianz Seg. S.A. } \\
\text { Cia Seg. Aliança do Brasil } \\
\text { S.A. } \\
\text { Itaú Seg. Auto Residência } \\
\text { HDI Seg. S.A. }\end{array}$ \\
\hline
\end{tabular}

Fonte: Dados da pesquisa.

O Quadro 7 traz a Perspectiva 11 dividida em: (i) Funções dos processos de supervisão: 
avaliação e revisão de todos os processos para o cumprimento das leis e normas administrativas; (ii) acesso e revisão do sistema de governança; e (iii) avaliação de todos os riscos e a capacidade de avaliação da empresa. A Bradesco Capitalização S.A. se destaca com enquadramento nas três subdivisões:

O processo de gerenciamento de riscos conta com a participação da Governança Corporativa desde a Alta Administração até as diversas áreas de negócios e produtos na identificação e gestão dos riscos. Adicionalmente, existem os Comitês Executivos definidos pelo Banco Bradesco para tratar os assuntos relacionados ao Risco de Crédito, Mercado, Liquidez, Legal e Operacional, que são submetidos ao Comitê de Gestão Integrada de Risco.

Quanto à capacidade de avaliação da empresa, a Allianz Seguradora destaca-se, declarando que "O gerenciamento de todos os riscos inerentes às atividades de modo integrado é abordado dentro de um processo apoiado na estrutura de Controles Internos, Auditoria Interna e Compliance". Esta diretriz tem o papel de delegar ao comitê a responsabilidade pela supervisão prudencial, baseada no gerenciamento de riscos e controles internos (WILLIAMS et al., 2015). Uma investigação das seguradoras holandesas realizada por De Haan e Kakes (2010) analisou as margens de solvência com os fatores de risco das seguradoras quando operam em regime de supervisão. A pesquisa descobriu que os níveis de solvência estão relacionados com as características de riscos e não com os requisitos regulamentares de solvência. A partir das diretrizes do Solvency II, os requisitos de solvência passaram a constituir o núcleo da supervisão prudencial da seguradora.

\subsection{Apetite ao Risco}

A seguir, as seguradoras enquadradas na Perspectiva 12.

\begin{tabular}{|c|c|c|}
\hline $\begin{array}{l}\text { Perfil da empresa quanto ao apetite } \\
\text { ao risco e à tolerância }\end{array}$ & $\begin{array}{l}\text { Quantidade e tipo de risco que } \\
\text { a organização está disposta a } \\
\text { buscar ou manter }\end{array}$ & $\begin{array}{c}\text { Quantidade e tipo de risco que a } \\
\text { organização está preparada para buscar, } \\
\text { aceitar ou tolerar }\end{array}$ \\
\hline $\begin{array}{l}\text { Bradesco Seguros S.A. } \\
\text { Caixa Capitaliz. S.A. } \\
\text { Metropolitan Life Seg. Prev. Priv. } \\
\text { S.A. } \\
\text { HSBC Seg. Br. S.A. } \\
\text { Safra Vida Prev. S.A. } \\
\text { Itaú Seg. Auto Residência } \\
\text { HDI Seg. S.A. }\end{array}$ & $\begin{array}{l}\text { IRB Brasil RE S.A. } \\
\text { Cia Seg. Aliança do Brasil S.A. }\end{array}$ & $\begin{array}{l}\text { Bradesco Capit. S.A. } \\
\text { Allianz Seg. S.A. } \\
\text { Cia Seg. Aliança do Brasil S.A. } \\
\text { Metropolitan Life Seg. Prev. Priv. S.A. } \\
\text { Safra Vida Prev. S.A. } \\
\text { Itaú Seg. Auto Residência } \\
\text { HDI Seg. S.A. }\end{array}$ \\
\hline
\end{tabular}

Fonte: Dados da pesquisa.

Para melhor entendimento da Perspectiva 12, o Quadro 8 foi estruturado com três divisões: (i) perfil da empresa quanto ao apetite ao risco e à tolerância ao risco; (ii) definição de apetite ao risco: quantidade e tipo de risco que a organização está disposta a buscar ou manter; e (iii) quantidade e tipo de risco que a organização está preparada para buscar, aceitar ou tolerar. A partir disso, onze seguradoras evidenciam seu perfil quanto a apetite e tolerância ao risco. A Bradesco Seguros S.A. se sobressai com o seguinte texto: "A Companhia avalia trimestralmente os seus riscos e a sua infraestrutura de controles internos, é formada por Comitês que avaliam todos os riscos (subscrição, crédito, mercado, liquidez, operacional e legal), define os limites de tolerância e elabora planos de mitigação, em conformidade com o

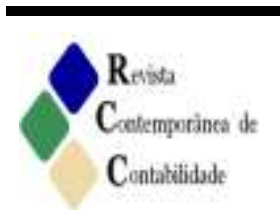


COSO e COBIT". Isso corrobora o estudo de Reij (2008), que menciona o risco operacional como um componente representativo do Solvency Capital Requirement (SCR).

No que diz respeito à definição de apetite ao risco, quantidade e tipo de risco que a organização está disposta a buscar ou manter, a Companhia de Seguros Aliança do Brasil assegura o seguinte: "a política da Companhia, em termos de exposição a riscos de mercado, é conservadora, sendo que (sic) os limites de risco de mercado são estabelecidos com base em cenários de stress, histórico e na metodologia de Value at Risk (VaR) e aprovados pelo Conselho de Administração. Diariamente a Gerência Financeira acompanha o resultado do VAR". Essa afirmação corrobora o que diz Chan (2010), baseada no novo acordo da Basileia, que introduziu métodos de apuração da necessidade mínima de capital mais sensível ao risco.

A quantidade e o tipo de risco que a organização está preparada para buscar, aceitar ou tolerar são notados na seguradora Safra Vida e Previdência S.A., com a seguinte nota explicativa:

A Companhia opera exclusivamente com o IRB-Brasil Resseguros. Este (sic) ressegurador possui um rating A (excelente) na avaliação de risco do segmento de seguros. Os tipos de contrato existentes compreendem basicamente excedente de responsabilidade conjugado com quota-parte. A Companhia adota uma política de repasse de riscos em resseguro e cosseguro, evitando que os sinistros de baixa frequência e valor elevado afetem a estabilidade do resultado de suas operações.

Para chegar ao parecer atendendo à diretriz do Solvency II, o atuário deve ter em conta a bondade de ajuste para o apetite de risco declarado da seguradora, tanto no que diz respeito ao nível de cobertura de resseguro em vigor e o risco de crédito resultante dos resseguradores utilizados. Isto inclui a clarificação do apetite de risco declarado da empresa, a política de resseguro declarada e a forma como ela se integra com o apetite pelo risco. Também pode incluir comentários sobre como as decisões de compra de resseguro são tomadas e como elas se enquadram dentro da estrutura geral de governança (WILLIAMS et al., 2015).

\subsection{Controles Internos para a Minimização de Riscos}

Por fim, está a utilização de controles internos para minimização de riscos, conforme a Perspectiva 13. A seguir, as 22 seguradoras enquadradas nessa perspectiva: Bradesco Seg. S.A., Bradesco Vida e Prev. S.A., Itaú Vida e Previdência S.A., Zurich Santander Brasil Seg. Prev. S.A., Itaú Seg. S.A., Caixa Vida e Prev. S.A., IRB Brasil RE S.A., HSBC Vida e Prev. Brasil S.A., Porto Seguro Cia Seg. Gerais S.A., Cia Itaú de Capitaliz. S.A., Bradesco AutoRE Cia Seg. S.A., Sul América Companhia Nacional Seg. S.A., Icatu Seguros AS., Mapfre Seg. S.A., Bradesco Capit. S.A., Sul América Seg. Pessoas e Prev. S.A., Allianz Seg. S.A., Cia Seg. Aliança do Brasil S.A., Paraná Cia Seg. S.A., Metropolitan Life Seg. Prev. Priv. S.A., HDI Seg. S.A. e Mapfre Vida S.A.

O disposto acima significa que $73,33 \%$ das seguradoras evidenciam a utilização de controles internos na mitigação dos riscos. A Bradesco Seguros S.A é uma das cinco seguradoras que expressam com maior detalhamento o cumprimento dessa perspectiva: "os processos são continuamente reavaliados e os testes de aderência, para aferir a efetividade dos controles existentes, regularmente aplicados, em conformidade com os principais frameworks de controles, como o COSO e o COBIT". O Quadro 9 contempla os textos selecionados das outras quatro seguradoras consideradas de destaque pela Perspectiva 13. 
Quadro 9 - Seguradoras em destaque pela Perspectiva 13

\begin{tabular}{|c|c|}
\hline Seguradora & Descrição das notas explicativas \\
\hline $\begin{array}{l}\text { Zurich Santander } \\
\text { Brasil Seg. prev. S.A. }\end{array}$ & $\begin{array}{l}\text { A Circular 249/2004 da Susep está relacionada à gestão eficaz do sistema de controles internos } \\
\text { direcionados à prevenção e à redução dos eventos de riscos e perdas operacionais. Anualmente, } \\
\text { a Zurich Santander Brasil Seguros e Previdência S.A. realiza, além do Teste de Adequação do } \\
\text { Passivo (nota 4.1), criteriosas avaliações atuariais de toda a sua carteira vigente para verificar a } \\
\text { solvência ou necessidade de reservas complementares. Através das ferramentas de controles } \\
\text { SOX, bem como as atividades pertinentes ao Plano de Continuidade aos Negócios, continuam } \\
\text { sendo prestadas pelo banco por meio de um SLA acordado entre as duas companhias }\end{array}$ \\
\hline $\begin{array}{l}\text { HSBC Vida e } \\
\text { Previdência Brasil } \\
\text { S.A. }\end{array}$ & $\begin{array}{l}\text { Monitora a exposição ao risco contra os limites previamente aprovados e reporta esses números } \\
\text { à Alta Administração do seu controlador, incluindo o Comitê de Investimentos e o ALCO (Assets } \\
\text { and Liabilities Committee). A medida-padrão, utilizada para quantificar o risco de mercado, é, } \\
\text { para risco de taxa de juros, a sensibilidade do valor presente líquido dos ativos e o fluxo de caixa } \\
\text { esperado do passivo para um basis point deslocando-se para cima paralelamente à taxa utilizada } \\
\text { para calcular o valor presente líquido }\end{array}$ \\
\hline $\begin{array}{l}\text { Sul América } \\
\text { Companhia Nacional } \\
\text { de Seguros S.A. }\end{array}$ & $\begin{array}{l}\text { A fundamentação para definição de componentes e ações essenciais a um processo organizado de } \\
\text { gestão de riscos, que culmine na consolidação de um Sistema de Controles Internos, tem levado } \\
\text { em consideração modelos de gerenciamento originados pelos pronunciamentos emitidos pelo } \\
\text { COSO - Committee of Sponsoring Organizations of the Treadway Commission. O Sistema de } \\
\text { Controles Internos e Gestão de Riscos Corporativos é baseado nessa metodologia, que concebe o } \\
\text { Sistema de Controles Internos como resultado de ações estruturadas, segundo oito componentes } \\
\text { que, inter-relacionados, constituem a base para uma estrutura integrada de riscos (ERM - } \\
\text { Enterprise Risk Management). O ERM pode ser percebido em duas formas: para satisfazer as } \\
\text { necessidades de controles internos e como um sistema completo, abrangente e integrado de } \\
\text { gerenciamento de riscos }\end{array}$ \\
\hline $\begin{array}{l}\text { Metropolitan Life } \\
\text { Seguros e Previdência } \\
\text { Privada S.A. }\end{array}$ & $\begin{array}{l}\text { A estrutura de controles internos realiza o gerenciamento de risco a fim de verificar riscos } \\
\text { operacionais, financeiros e estratégicos. O sistema de controles internos passa por um processo } \\
\text { periódico de avaliação e testes. A metodologia adotada consiste no mapeamento dos principais } \\
\text { processos e subprocessos baseados no modelo COSO }\end{array}$ \\
\hline
\end{tabular}

Fonte: Dados da pesquisa.

O Quadro 9 pode responder à questão de pesquisa do estudo de Reij (2008), no qual ele argumenta quais técnicas estão disponíveis e úteis para as seguradoras administrarem o risco da taxa de juros a fim de reduzir o requisito de capital de solvência para o risco de mercado.

Conforme evidenciado pelas companhias em discussão, embora os modelos de negócios das companhias de seguros possam diferir, os fundamentos da governança de risco operacional e os quadros de controle interno permanecem comparáveis. Isto pode ser visto nas estruturas das companhias de seguros. Dessa forma, a função dos controles internos das seguradoras pode expressar as políticas de subscrição geral ou sobre a adequação de acordos de seguros e resseguros (WILLIAMS et al., 2015).

\section{Conclusão}

O objetivo proposto foi analisar o panorama do mercado segurador brasileiro em relação à regulamentação internacional de solvência. A presente pesquisa teve como principal constatação, corroborada por Deighton et al. (2009), a de que, embora haja uma crescente conscientização das partes interessadas na governança e gestão de risco das seguradoras brasileiras, ainda é necessário haver melhorias.

Quanto às informações de avaliação de risco e solvência, identificou-se que foram evidenciadas de forma bastante limitada, cumprindo, de certa forma, as exigências da Susep. Poucas empresas detalharam o perfil de risco específico, os limites de tolerância de risco, bem como explicações acerca das provisões técnicas.

No âmbito da Perspectiva 2, de forma geral, as seguradoras explicitam os métodos

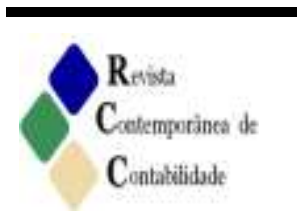


utilizados de avaliação de riscos, e os métodos mais citados foram o VAR e o Stress Testing. Quanto à avaliação de risco e solvência como parte integrante da estratégia de negócio, apenas 14 seguradoras publicaram informações de tal prática. Quanto à frequência da avaliação do risco, algumas seguradoras avaliam anualmente, outras trimestralmente.

No que diz respeito à Perspectiva 5, apenas as seguradoras Caixa Seguradora S.A. e Safra Vida e Previdência S.A. declaram que os resultados de cada avaliação de risco e solvência são comunicados às autoridades de supervisão. Entretanto, entende-se que todas as seguradoras cadastradas na Susep informam as autoridades competentes, caso contrário estariam em processo de intervenção.

Dentro da Perspectiva 6, 16 seguradoras divulgam informações detalhadas sobre o requisito mínimo de capital de solvência. Apenas duas seguradoras - Bradesco Vida e Prev. S.A. e Mapfre Vida S.A. - possuem sistema de alerta de riscos. Quanto à competência e idoneidade, cabe ressaltar a limitação da análise por ser de natureza subjetiva, e apenas sete seguradoras divulgaram de forma clara a solidez dos controles internos como mecanismos de mitigação de riscos. Outrossim, apenas sete seguradoras afirmaram que a auditoria interna é responsável por cálculos atuariais. A auditoria no diálogo entre a governança e a supervisão foi mencionada por dez seguradoras.

$\mathrm{Na}$ Perspectiva 11, percebe-se que a maioria das seguradoras possui algum tipo de supervisão no processo de avaliação de riscos. Apenas 11 seguradoras evidenciam seu perfil quanto a apetite ou tolerância ao risco. E, por fim, os controles internos utilizados para a minimização de riscos, mesmo com a regulamentação internacional do Solvency II, nem todas as seguradoras divulgam o papel (ou a existência) de seus controles internos.

Ressalta-se, ainda, corroborando Ilic, Avdalovic, Obadovic (2011), que em nenhum momento se observou preocupação das seguradoras quanto à avaliação equivocada do risco de seguro. Outra constatação advém do estudo de Vavrova e Slova (2012), o qual afirmou que as seguradoras checas detêm mais capital do que o exigido pelo Solvency II e têm recursos suficientes para obrigações futuras. Na presente pesquisa não foi calculado o capital mínimo requerido na base do Solvency II. No entanto, nenhuma seguradora pesquisada demonstrou dificuldades quanto aos limites de capital mínimo requerido.

Com a implementação do Solvency II em andamento no Brasil, as diretivas do Solvency II têm a função atuarial de introduzir a ideia de que a seguradora tem responsabilidades sobre a prestação relativas às provisões técnicas, um parecer sobre a adequação do resseguro, um parecer sobre a política de subscrição e contribuindo para o sistema de gestão de riscos. Este estudo destaca o panorama do mercado segurador brasileiro a partir de uma perspectiva qualitativa. Evidências no presente estudo sugerem que tanto a atitude dos gestores quanto as medidas prudenciais de risco e segurança da informação podem ser elementos fundamentais na promoção de formação e educação da estratégia prudencial na gestão de riscos.

\section{Referências}

ALVES, F. J. C. O Euro e o rating. Instituto de Seguros de Portugal. ISP, ISSN 0873-6685, A. 2, n. 6, p. 3-6. Lisboa, jun 1998. Disponível em:

$<$ http://www.isp.pt/winlib/cgi/winlibimg.exe?key=\&doc=8629\&img=972>. Acesso em: 21 mar. 2013.

AZIZ, N. A. A. Managing corporate risk and achieving internal control through statutory compliance. Journal of Financial Crime, v. 20, n. 1, p. 25-38. 2012.

$<$ http://dx.doi.org/10.1108/13590791311287328>. 
BADEA, D. G.; NOVAC, L. E. Risk management - to become or should become a competitive advantage for the Romanian insurance companies. The Bucharest Academy of Economic Studies, v.1, n.1, p. 57-65, 2001.

BARDIN, L. Análise de Conteúdo. Lisboa, Portugal: Edições 70, 1977.

BEASLEY, M. S.; CLUNE, R.; HERMANSON, D. R. Enterprise risk management: an empirical analysis of factors associated with the extent of implementation. Journal of Accounting and Public Policy, v. 24, n. 6, p. 521-531, 2005.

http://dx.doi.org/10.1016/j.jaccpubpol.2005.10.001.

BRYCE, C. et al. Should the insurance industry be banking on risk escalation for Solvency II?. International Review of Financial Analysis, v. 46, p. 131-139, 2016. http://dx.doi.org/10.1016/j.irfa.2016.04.014.

CARVALHO, D. B.; CALDAS, M. P. Basiléia II: abordagem prática para acompanhamento de risco operacional em instituições financeiras. Resenha BM\&F-169, São Paulo: Febraban, p. 76-84, 2008.

CEIOPS - Committee of European Insurance and Occupational Pensions Supervisors. Own Risk and Solvency Assessment (ORSA). 2008. Disponível em:

$<$ https:/eiopa.europa.eu/fileadmin/tx_dam/files/consultations/IssuesPaperORSA.pdf $>$. Acesso em: 21 abr. 2013.

CHAN, L. B. Risco de subscrição frente às regras de solvência do mercado segurador brasileiro. 2010. 99 p. Tese (Doutorado em Contabilidade) - Programa de Pós-Graduação em Economia, Administração e Contabilidade, Universidade de São Paulo, São Paulo.

; SILVA, F. L. da; MARTINS, G. de A. Novas regras de solvência no mercado segurador brasileiro: uma reflexão acerca do modelo adotado. In: Congresso USP Iniciação Científica em Contabilidade, 5., 2008, Anais..., São Paulo. Disponível em: <www.congressousp.fipecafi.org/artigos82008/296.pdf>. Acesso em: 20 mar. 2013.

COMISIÓN DE LAS COMUNIDADES EUROPEAS. Propuesta de directiva del Parlamento Europeo Y Del Consejo - sobre el seguro de vida el acceso a la actividad de seguro y de reaseguro y su ejercicio - Solvencia II. Bruxelas, 2007. Disponível em: $<$ http://eurlex.europa.eu/legal-content/ES/ALL/?uri=celex:32013L0058>. Acesso em: 20 mar. 2013.

\section{COMMITTEE OF SPONSORING ORGANIZATIONS OF THE TREADWAY}

COMMISSION - COSO. Enterprise risk management integrated framework. New York:

COSO, 2004. Disponível em: <http://www.theiia.org/download.cfm? file=9229>. Acesso em: 23 fev. 2013.

. Disponível em: <http://www.coso.org/-erm.htm>. Acesso em: 21 abr. 2013.

. Gerenciamento de Riscos Corporativos - Estrutura Integrada (Enterprise Risk

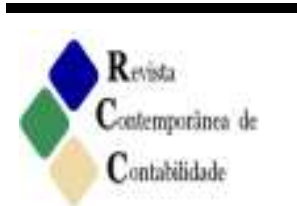


Management - Integrated Framework). New York: COSO, 2004. Disponível em:

$<$ http://www.coso.org/documents/COSO_ERM_ExecutiveSummary_Portuguese.pdf $>$.

Acesso em: 20 fev. 2013.

CUMMINS, D.; HARRINGTON, S.; NIEHAUS, G. An economic overview of risk-based capital requirements for the property-liability industry. Journal of Insurance Regulation, v. 11, n. 4, p.427-447, 1994.

DE HAAN, L.; KAKES, J. Are non-risk based capital requirements for insurance companies binding? Journal of Banking \& Finance, v. 34, n. 7, p. 1618-1627, 2010.

http://dx.doi.org/10.1016/j.jbankfin.2010.03.008.

DEIGHTON, S. P. et al. Governance and risk management in United Kingdom insurance companies. British Actuarial Journal, v. 15, n. 03, p. 503-556, 2009.

https://doi.org/10.1017/S1357321700005729.

DOFF, R. Defining and measuring business risk in an economic-capital framework. The Journal of Risk Finance, v. 9, n. 4, p. 317-333, 2008.

http://dx.doi.org/10.1108/15265940810894990.

EHRLICH, Kathleen. ORSA - Own risk and solvency assessment preparations can start. Solvency Consulting Knowledge Series, v. 1 n. 302, p.1-4, August, 2012. Disponível em: $<$ https://www.munichre.com/site/corporate/get/documents_E-

1114564912/mr/assetpool.shared/Documents/5_Touch/_Püblications/302-07574_en.pdf >. Acesso em: 21 abr. 2013.

ELING, M.; PANKOKE, D. Discontinued business in non-life insurance: an empirical test of the market development in the German-speaking countries. European Actuarial Journal, v. 4, n. 1, p. 31-48, 2014. DOI: 10.1007/s13385-013-0084-6.

ERNST \& YOUNG. Solvência II e impactos no sistema de governança das seguradoras. Seminário de Controles Internos \& Compliance, Auditoria e Gestão de Riscos. São Paulo, 24 de setembro de 2009. Disponível em: <http://www.ey.com/Publication/vwLUAssets/ORSAReadiness_Brochure/\$FILE/ORSA-Readiness_Brochure.pdf>. Acesso em 21 abr. 2013.

EUROPÉEN GROUPE CONSULTATIF ACTUARIEL. Solvency II Glossary. Comité Européen des Assurances-Groupe Consultatif Actuariel Européen. Brussels, March 2007. Disponível em:

$<$ http://ec.europa.eu/internal_market/insurance/docs/solvency/impactassess/annexc08d_en.pdf $>$. Acesso em: 19 abr. 2013.

FLORYSZCZAK, A.; LE COURTOIS, O.; MAJRI, M. Inside the Solvency 2 black box: net asset values and solvency capital requirements with a least-squares Monte-Carlo approach. Insurance: Mathematics and Economics, v. 71, p. 15-26, 2016. http://dx.doi.org/10.1016/j.insmatheco.2016.07.005.

; LE COURTOIS, O.; MAJRI, M. Inside the Solvency 2 black box: net asset values and solvency capital requirements with a least-squares Monte-Carlo approach. Disponível em: 
SSRN 2537408, 2014. http://dx.doi.org/10.1016/j.insmatheco.2016.07.005.

FORWARD FOCUS. Insurance issues and insights from Howard Mills. The Own Risk and Solvency Assessment (ORSA) - A regulatory guidepost to the future. Insurance issues and insights from Howard Mills. 2012. Disponível em:

$<$ http://www.deloitte.com/assets/DcomBermuda/Local\%20Assets/Documents/Forward\%20Fo cus\%20ORSA\%20Final.pdf>. Acesso em: 21 mar. 2013.

GONZÁLEZ, L. O. et al. Estimación de las necesidades de capital mediante modelos internos alternativos al propuesto en Solvencia II (QIS4). Spanish Journal of Finance and Accounting/Revista Española de Financiación y Contabilidad, v. 40, n. 149, p. 9-34, 2011. http://dx.doi.org/10.1080/02102412.2011.10779696.

GORDON, L. A.; LOEBA, M. P.; TSENG, C. Y. Enterprise risk management and firm performance: A contingency perspective. Journal of Accounting and Public Policy. v. 28, n. 4, p. 301-327, 2009. http://dx.doi.org/10.1016/j.jaccpubpol.2009.06.006.

IAIS - International Association of Insurance Supervisors. 2012. Disponível em: $<$ http://www.iaisweb.org/Home-2>. Acesso em: 21 mar. 2013.

ILIC, M. M; AVDALOVIC, V.; OBADOVIC M. D. Development of model for insurance risk management and its application to insurance companies operating in the Serbian market. Journal of Business Management and Economics. v. 2, n. 6, p. 223-228, 2011.

IMONIANA, J. O.; NOHARA, J. J. Cognição da estrutura de controle interno: uma pesquisa exploratória. Base, v. 2, n. 1, p. 37-46, 2005.

INTOSAI, GOV 9100. Guidelines for internal controls standards for the public sector. Austrian Court of Audit, VIENNA. Disponível em: $<$ http://www.issai.org/media(574, 1033)/INTOSAI_GOV_9100_E.pdf >. Acesso em: 23 fev. 2013.

JAUCH, L. R.; OSBORN, R. N.; MARTIN, T. N. Structured content analysis of cases: A complementary method for organizational research. Academy of Management Review, v. 5, n. 4, p. 517-525, 1980. DOI: 10.5465/AMR.1980.4288954.

JEDNAK, D.; JEDNAK, J. Operational Risk Management in Financial Institutions. Management, v. 66, p. 66-80, 2013. DOI: 10.7595/management.fon.2013.0004.

LIEBWEIN, P. Risk models for capital adequacy: Applications in the context of solvency II and beyond. The Geneva Papers on Risk and Insurance-Issues and Practice, v. 31, n. 3, p. 528-550, 2006. Doi:10.1057/palgrave.gpp.2510095.

LÓPEZ, M. V. R.; PÉREZ-FRUCTUOSO, M. J.; MARTÍN, J. M. Definición de un modelo dinámico de gestión y cuantificación del riesgo operacional para las entidades aseguradoras. Gerencia De Riesgos Y Seguros. Madrid: Fundación Mafre Estudios, v. 3, n. 105, p. 24-43, 2009.

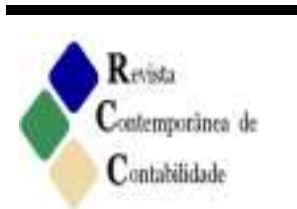


MANGO, D. An Introduction to insurer strategic risk topic 1: risk management of an insurance enterprise. Enterprise Risk Analysis, Guy Carpenter \& Company, p. 144-172, 2007.

MARTINS, A. P. da S. C. Análise de pressupostos para definição de um modelo interno no âmbito da Solvência II. 2009. 114 p. Tese (Doutorado em Matemática e Aplicações) Programa de Pós-Graduação da Faculdade de Ciências e Tecnologia (FCT), Universidade Nova de Lisboa, Lisboa.

MEYRICKE, R.; SHERRIS, M. Longevity risk, cost of capital and hedging for life insurers under Solvency II. Insurance: Mathematics and Economics, v. 55, p. 147-155, 2014. http://dx.doi.org/10.1016/j.insmatheco.2014.01.010.

MOLOI, T. Key mechanisms of risk management in South Africa's national government departments: The public-sector risk management framework and the King III Benchmark. International Public Administration Review, v. 14, n. 4, p. 37-52, 2016. DOI: 10.17573/ipar.2016.2-3.02.

NEVES, C. da R. Solvência II no mercado brasileiro de seguros: requerimento de capital de solvência. SUSEP. 2010. Disponível em: <http://www.febraban.org.br/>. Acesso em: 10 mar. 2013.

PLAT, R. Essays on valuation and risk management for insurers. Disponível em: $<$ http://ssrn.com/abstract $=1706027>.2010$

REIJ, Nicole F.S.V. Managing market risks for Dutch insurers. 2008. $84 \mathrm{f}$. Thesis (Master of Science in Quantitative Finance and Actuarial Science), Faculty of Economics and Business Administration, Tilburg University, Tilburg, 2008.

SLYWOTZKY, Adrian J.; DRZIK, John. Countering the biggest risk of all. Harvard Business Review, v. 83, n. 4, p. 78-88, 133, 2005.

SZCZEPAŃSKI, R.; SZCZEPAŃSKA, J. Ś. Risk management system in business relationships: Polish case studies. Industrial Marketing Management, v. 41, n. 5, p. 790799, 2012. http://dx.doi.org/10.1016/j.indmarman.2012.06.003.

TAYLOR, P. ORSA for dummies: ORSA - the heart of Solvency II. Institute of Risk Management Solvency II Group. University of Oxford: Oxford University Press, Apr. 2012.

TORRE-ENCISO, M. I. M.; BARROS, R. H. Operational risk management for insurers. International Business Research, v. 6, n. 1, 2012. http://dx.doi.org/10.5539/ibr.v6n1p1.

VAVROVA, E.; SLOVA, K. Insurance conditions for environmental liability. Acta Academica Karviniensia, v. 1, n.1, p. 111-121, 2012.

WILLIAMS, R. L. et al. Application of the Solvency II actuarial function to general insurance firms: by the Actuarial Function Working Party. United Kingdom: Institute and Faculty of Actuaries, 2015. 
WOLFERT. Disponível em: <http://itweb.com.br/voce-informa>. Acesso em 2011.

YANAKA, G. M.; HOLLAND, M. Basiléia II e exigência de capital para risco de crédito dos bancos no Brasil. Revista Brasileira de Finanças, v. 8, n. 2, p. 167-195, 2010. 